\title{
How important are atmospheric depressions and mobile cyclones for emitting mineral dust aerosol in North Africa?
}

\author{
S. Fiedler ${ }^{1, *}$, K. Schepanski ${ }^{2}$, P. Knippertz ${ }^{1, *}$, B. Heinold ${ }^{2}$, and I. Tegen ${ }^{2}$ \\ ${ }^{1}$ School of Earth and Environment, University of Leeds, LS2 9JT Leeds, UK \\ ${ }^{2}$ Leibniz Institute for Tropospheric Research (TROPOS), Permoser Str. 15, 04318 Leipzig, Germany \\ * now at: Institute for Meteorology and Climate Research (IMK-TRO), Karlsruhe Institute of Technology (KIT), \\ Wolfgang-Gaede-Str. 1, 76131 Karlsruhe, Germany \\ Correspondence to: S. Fiedler (stephanie.fiedler@kit.edu)
}

Received: 6 November 2013 - Published in Atmos. Chem. Phys. Discuss.: 10 December 2013

Revised: 4 July 2014 - Accepted: 11 July 2014 - Published: 1 September 2014

\begin{abstract}
This study presents the first quantitative estimate of the mineral dust emission associated with atmospheric depressions and mobile cyclones in North Africa. Atmospheric depressions are automatically tracked at $925 \mathrm{hPa}$ based on ERA-Interim data from the European Centre for MediumRange Weather Forecasts for 1989-2008. A set of filter criteria is applied to identify mobile cyclones, i.e. migrating and long-lived cyclones. The shorter term cyclone is used as a synonym for mobile cyclones. Dust emission is calculated with a dust emission model driven by $10 \mathrm{~m}$ winds and soil moisture from ERA-Interim. Emission peaks during winter and spring with spatial averages of $250-380 \mathrm{~g} \mathrm{~m}^{-2}$ per month. Comparison of the dust source activation frequency from the model against SEVIRI satellite observation shows a good agreement in the Bodélé Depression but differences in the north and west of North Africa. Depressions are abundant, particularly in summer when the Saharan heat low is situated over West Africa and during spring in the lee of the Atlas Mountains. Up to $90 \%$ (55\% annually and spatially averaged) of dust emission occurs within 10 degrees of these depressions, with embedded mechanisms such as nocturnal low-level jets playing a role. Cyclones are rarer and occur primarily north of $20^{\circ} \mathrm{N}$ in spring in agreement with previous studies and over summertime West Africa consistent with near-surface signatures of African Easterly Waves. Dust emission within 10 degrees of cyclones peaks over Libya with up to $25 \%$ in spring. Despite the overall small contribution of $4 \%$ annually and spatially averaged, cyclones coincide with particularly intense dust emission events exceeding the climatological mean by a factor of four to eight. Soil
\end{abstract}

moisture weakens dust emission during cyclone passage by about $10 \%$.

\section{Introduction}

The accurate simulation of mineral dust aerosol in the Earth system is one of the great challenges of current atmospheric research. Dust aerosol is important due to its proposed but uncertain effects on the radiation transfer in the atmosphere with implications for the water and energy cycle, as well as effects on ecosystems and humans (Carslaw et al., 2010; Shao et al., 2011; Knippertz and Todd, 2012, and references therein). Despite these impacts of dust aerosol, estimates of the annual total of dust emission from state-of-the-art climate models vary from 400 to $2200 \mathrm{Tg}$ for North Africa (Huneeus et al., 2011), the largest dust source on Earth. Further reduction of this modelling uncertainty depends on improving the representation of dust emission. Both the realistic description of soil properties and meteorological mechanisms for peak wind generation are important. The wind speed near the surface is particularly crucial as it controls the onset of dust emission, and the magnitude of the flux non-linearly (e.g. Kok et al., 2012; Marticorena and Bergametti, 1995; Tegen et al., 2002).

A systematic analysis of mechanisms generating peak winds strong enough for mobilizing dust provides the basis for evaluating dust emission from atmospheric models. Knippertz and Todd (2012) review the literature on relevant meteorological processes for dust emission. Recently a 
number of studies have addressed the relative importance of meteorological processes for dust emission focusing on the meso-scale. Cold pool outflows from convective downdrafts (haboobs) are suggested as an important dust storm type in summertime West Africa (e.g. Marsham et al., 2011, 2013; Heinold et al., 2013). A 40-day horizontally high-resolved simulation suggests that haboobs generate about half of the dust aerosol amount in this region, but a physical parameterization for atmospheric models with coarse spatial resolution is currently missing (Heinold et al., 2013). Another important process for dust emission is the nocturnal low-level jet (NLLJ), which frequently forms in North Africa (Schepanski et al., 2009; Fiedler et al., 2013). Based on a 32-year climatology, up to $60 \%$ of the dust emission is associated with NLLJs in specific regions and seasons (Fiedler et al., 2013).

The main meteorological driver for the largest dust emission amount of the continent that occurs north of $20^{\circ} \mathrm{N}$ between December and May (Fiedler et al., 2013), however, is not well quantified. During this time of year cyclones affect the region (e.g. Alpert and Ziv, 1989; Winstanley, 1972; Hannachi et al., 2011). The core of these cyclones can either lie over the continent itself or further north in the Mediterranean region (e.g. Maheras et al., 2001; Schepanski and Knippertz, 2011). Several studies suggest that cyclones can cause dust storms (Bou Karam et al., 2010; Hannachi et al., 2011; Schepanski et al., 2009; Schepanski and Knippertz, 2011), although a case study by Knippertz and Fink (2006) for the exceptionally strong and continental-scale dust storm in March 2004 gives evidence that a cyclone only produces one part of the associated dust emission. The remaining dust mobilization is linked to strong northeasterly Harmattan winds. These Harmattan surges manifest themselves by an increased horizontal pressure gradient between the post cold frontal ridge and the prevailing low pressure over the continent. Both the cyclone and the Harmattan surge are usually caused by a wave at upper-tropospheric levels. While the trough is typically associated with the cyclone, the ridge to the west of it can cause the strengthening of anticyclonic conditions over wide areas of North Africa, which increases the northeasterly Harmattan winds. Harmattan surges may reach almost continental scale and cause dust emission - typically involving the NLLJ mechanism - as far south as the Bodélé Depression and the West African Sahel (Knippertz and Todd, 2010). The dust may than be transported towards the Atlantic Ocean and beyond. Klose et al. (2010) show that about half of dust suspended over the Sahel may be linked to a pressure pattern typical of Harmattan surges: a low over the Arabian Peninsula and the Azores High expanding eastwards into the continent. The mass of dust emission associated with cyclones has not been estimated before. The aim of the present study is to reveal how much dust emission is linked to migrating cyclones affecting North Africa.

Previous work on cyclones influencing North Africa focus on the meteorological analysis in the Mediterranean basin. Alpert et al. (1990) use five years of analysis data from the European Centre for Medium-Range Weather Forecasts (ECMWF) for analysing Mediterranean cyclones statistically. A longer time period of 18 years of ECMWF reanalysis is exploited by Trigo et al. (1999) for cyclone tracking. The contributing factors of cyclogenesis in the Mediterranean region is investigated later by Trigo et al. (2002). Maheras et al. (2001) present a 40-year climatology of surface cyclones based on re-analysis from the National Centers for Environmental Prediction (NCEP) and underline the variability of both the position and the core pressure of cyclones with the time of day. Since the method does not have a criterion for cyclone migration, the climatology by Maheras et al. (2001) includes heat lows and orographic-induced depressions. NCEP data are also used for a springtime climatology of cyclones north of $20^{\circ} \mathrm{N}$ for 1958-2006 (Hannachi et al., 2011). Hodges et al. (2011) compares cyclone climatologies derived from state-of-the-art re-analysis showing spatial differences of track densities and cyclone intensity. All of these studies highlight distinct regions that are prone to frequent cyclogenesis. These are over the Aegean Sea, the Gulf of Genoa and the Black Sea (e.g. Trigo et al., 2002). Regions of frequent cyclogenesis in northern Africa lie to the south of the Atlas Mountains, and east of the Hoggar Mountains (Alpert and Ziv, 1989; Trigo et al., 1999; Maheras et al., 2001; Schepanski and Knippertz, 2011; Winstanley, 1972). Cyclones may further form or intensify over Libya, also termed Sharav or khamsin cyclones (e.g. Alpert and Ziv, 1989) which are thought to be the main driver for dust transport towards the eastern Mediterranean (Moulin et al., 1998; Winstanley, 1972). Classically the term Sharav is used for heat waves in Israel, for which cyclones from Africa are one of the meteorological conditions (Winstanley, 1972). Most of the cyclones in the Mediterranean basin form between December and May, when the temperature contrast between land and sea is largest.

Cyclogenesis in Northwest Africa occurs east of an upperlevel trough where positive vorticity advection supports the formation of a depression near the surface. These troughs advect cool air masses at their western side towards the $\mathrm{Sa}$ hara and transport Saharan air northwards at their eastern side (e.g. Maheras et al., 2001; Knippertz and Fink, 2006). The interaction with orography can lead to cyclogenesis at the lee side of mountain ranges. In North Africa, the position of lee cyclogenesis is typically the southern side of the Atlas Mountains (e.g. Schepanski and Knippertz, 2011; Trigo et al., 2002). Migrating lee cyclones usually follow east- to northeastward trajectories with propagation speeds around $10 \mathrm{~m} \mathrm{~s}^{-1}$ (e.g. Alpert and Ziv, 1989; Alpert et al., 1990; Bou Karam et al., 2010; Hannachi et al., 2011). They can advect hot, dry and dusty air towards the eastern Mediterranean, but may also bring rainfall (Winstanley, 1972) with flood risk in Israel (Kahana et al., 2002). Unusually deep cyclones over the western Mediterranean that move from Algeria northwards are documented for winter that can cause 
high impact weather (Homar et al., 2002; Homar and Stensrud, 2004; Homar et al., 2007).

In contrast to cyclones at the northern fringes of the continent, low latitudes are characterized by shallow depressions. Horizontal pressure gradients during the presence of depressions can be large enough to generate dust storms (Winstanley, 1972; Hannachi et al., 2011). Depressions in the form of heat lows build in response to strong solar irradiation, the location of which changes in the course of the year. In North Africa the heat low moves from positions near the equator in the east between November and March towards West Africa between April and October (Lavaysse et al., 2009). The Saharan heat low during summer is typically quasi-stationary over several days to weeks (Lavaysse et al., 2009; Todd et al., 2013) and coincides with high concentrations of dust aerosol (e.g. Knippertz and Todd, 2010). The heat low strongly affects the positions of the intertropical discontinuity (ITD), where the northeasterly Harmattan winds and the southeasterly monsoon winds converge. Bou Karam et al. (2009) suggest that the ITD plays a role for emitting dust aerosol and uplifting of aged dust plumes.

A migrating depression type originating in low latitudes is the Sudan-Sahara depression the concept of which is described in classical literature and has recently been revised (Schepanski and Knippertz, 2011, and references therein). These depressions form in the central Sahara, usually southwest of the Tibesti Mountains. They initially migrate westwards before turning anticyclonically over West Africa to track eastwards over northern parts of the continent. Analysis of 20 years of ECMWF ERA-Interim re-analysis suggests that Sudan-Sahara depressions are rare and too shallow to cause sufficiently high wind speeds for significant amounts of dust emission (Schepanski and Knippertz, 2011).

Other migrating depressions at low latitudes are surface signatures of African easterly waves (AEWs). Based on upper-air soundings, Burpee (1972) shows that AEWs form south of the African easterly jet (AEJ) at $700 \mathrm{hPa}$ along $10^{\circ} \mathrm{N}$. The AEJ results from the horizontal temperature contrast between the hot Saharan air poleward and the cooler air masses equatorward of the AEJ. Burpee (1972) suggests that the wind shear at the AEJ is the origin of wave-like disturbances. More recent work indicates deep convection (e.g. Mekonnen et al., 2006; Thorncroft et al., 2008) and extratropical influence (Leroux et al., 2011) as trigger of AEWs. The main genesis region of AEWs remains controversial and ranges from 10 to $40^{\circ} \mathrm{E}$ (Burpee, 1972; Mekonnen et al., 2006; Thorncroft and Hodges, 2000; Thorncroft et al., 2008, and references therein) from where they propagate westwards with the mean flow. AEWs occur about every 3 to 5 days between June and September with a peak activity at the beginning of August (Burpee, 1972; Jones et al., 2003). At $850 \mathrm{hPa}, \mathrm{AEW}$ signatures occur both north and south of the AEJ axis at 10 and $20^{\circ} \mathrm{N}$ (Mekonnen et al., 2006). They are most frequently found in West Africa with up to six events between May and October around $20^{\circ} \mathrm{N}$ and $10^{\circ} \mathrm{W}$ (Thorncroft and Hodges, 2000). AEWs are linked to variability of dust mobilization and concentration over West Africa although the diurnal cycle seems similarly important (Luo et al., 2004). Knippertz and Todd (2010) argue that dust emission associated with AEWs is driven by embedded haboobs and NLLJs. Predominant emission in the late afternoon and evening is an indication for haboobs (Marsham et al., 2011; Heinold et al., 2013) while morning emissions can be linked to the breakdown of NLLJs (Schepanski et al., 2009; Fiedler et al., 2013). AEWs are also important for atmospheric transport of dust aerosol (Jones et al., 2003) and are linked to tropical cyclone formation (e.g. Hopsch et al., 2007).

The presence of soil moisture can have important implications for dust emission (Fecan et al., 1999). An increase of soil moisture strengthens the bonding forces between soil particles constraining higher wind speeds for dust emission (Cornelis and Gabriels, 2003; Fecan et al., 1999). While precipitation amounts and therefore soil moisture are generally small in large areas of the Sahara, cyclones are an important source for rainfall in North Africa (Hannachi et al., 2011) and may be able to moisten the soil sufficiently to increase the threshold of dust emission onset. This soil moisture effect is predominantly expected for cyclones along the North African coast between December and May, and near-surface signatures of AEWs at the southern fringes of the Sahara desert between May and September. The magnitude of the soil moisture effect during cyclone passage is, however, not well quantified.

The present study is the first climatological estimate of the mass of emitted dust aerosol associated with depressions and migrating, long-lived cyclones in North Africa. The latter are herein a sub-class of atmospheric depressions. Depressions are defined as minima in the geopotential height at $925 \mathrm{hPa}$ that are identified and tracked with an automatic algorithm. Minima in the field of geopotential height are termed cyclones if they migrate, live for more than 2 days, and have a decreasing core pressure at the beginning of their life cycle. The depression and cyclone tracks are combined with dust emission calculations driven by ECMWF ERA-Interim data. Details of the method are explained in Sect. 2. Section 3 presents the results for the climatology of depressions and cyclones for dust emission. Conclusions are drawn in Sect. 4.

\section{Method}

\subsection{Depression and cyclone identification}

The present study uses the depression tracks over North Africa for 1989-2008 retrieved by Schepanski and Knippertz (2011). Schepanski and Knippertz (2011) investigate Sudan-Sahara depressions by using the tracking algorithm from Wernli and Schwierz (2006) with modifications for low latitudes. Threshold values are adapted and the original input 
fields of mean sea level pressure are replaced by the geopotential height at $925 \mathrm{hPa}$ that represents North African conditions better. The automated algorithm determines minima relative to the adjacent grid cells and is applied to the ERAInterim re-analysis with a horizontal resolution of $1^{\circ}$ (Dee et al., 2011). Even though the input data set is 6-hourly, minima are identified daily at 00:00 UTC in order to avoid erroneous tracking caused by the large diurnal cycle of the geopotential height at low levels over North Africa (Schepanski and Knippertz, 2011). The influence of the time of day on a depression identification is shown by Maheras et al. (2001).

Once a minimum is identified, the corresponding area of the depression is determined by the closed contour that lies furthest away from the centre. The value of the contour interval is 4 geopotential meter (gpm) corresponding to about $0.5 \mathrm{hPa}$ (Schepanski and Knippertz, 2011). Depressions are connected to a track if two consecutive positions lie within $1000 \mathrm{~km}$. This criterion allows for a maximum speed of $11.6 \mathrm{~m} \mathrm{~s}^{-1}$ that is sufficient for the majority of systems in North Africa (Schepanski and Knippertz, 2011).

The investigation of depressions and migrating cyclones over North Africa presented here is broader than that by Schepanski and Knippertz (2011). Here, depressions are all identified minima in the geopotential height at $925 \mathrm{hPa}$ without a geographical restriction. The selection of migrating cyclones from all identified depressions requires generalized criteria applicable for the entire domain and time period. Note that migrating cyclones include both near-surface signatures of AEWs and cyclones. Both are termed cyclones in this paper and identified by the following filter criteria that have to be fulfilled simultaneously.

1. Cyclones have to be identified in at least three consecutive nights reflecting a life time of $48 \mathrm{~h}$ as the minimum time period for a complete life cycle of a cyclone. This assumption complies with life times given in the literature (Hannachi et al., 2011; Bou Karam et al., 2010).

2. Each cyclone has to propagate over a pre-defined horizontal distance between genesis and lysis. The mean propagation speed is defined as the maximum displacement during the life time of the system calculated from the range of longitudes and latitudes of centre positions. The threshold for the propagation speed is $5^{\circ}$ per day corresponding to a mean cyclone speed of $5-6 \mathrm{~m} \mathrm{~s}^{-1}$. This generous criterion is well below migration speeds reported for cyclones over North Africa (Alpert and Ziv, 1989; Bou Karam et al., 2010; Knippertz and Todd, 2010; Schepanski and Knippertz, 2011).

3. The propagation speed alone does not successfully exclude all identified cases of the Saharan heat low, the mean position of which migrates over time. In order to exclude most heat lows, the identified cyclones have to have a decreasing core pressure between the first and second night. This criterion reflects cyclogenesis and successfully reduces the number of identified cyclones in summertime West Africa. Tracks of filling cyclones in the Mediterranean region are also excluded by this criterion, particularly frequent in the east during spring. Sensitivity tests show that reducing the number of cyclones in the Mediterranean basin has a negligible effect on the dust emission coinciding with cyclones (Sect. 3.6). This suggests that filling cyclones with centres away from dust sources do not generate wind speeds sufficiently large for mobilizing dust.

\subsection{Dust emission}

Mineral dust emission is calculated for 1989-2008 with the dust emission model of Tegen et al. (2002) following the experiment setup in Fiedler et al. (2013). This dust emission scheme is validated by Tegen et al. (2002) and used in both global and regional climate models (Heinold et al., 2011; Zhang, 2012). Here, the dust model is driven by 3hourly $10 \mathrm{~m}$ wind speed and soil moisture of the uppermost soil layer from ERA-Interim forecasts (Dee et al., 2011). These forecasts are for $12 \mathrm{~h}$, are initialized at 00:00 and 12:00 UTC, and interpolated onto a horizontal grid of $1^{\circ}$. ERA-Interim re-analysis produces the best diurnal cycle of wind speed amongst state-of-the-art re-analysis projects compared to flux tower observations over land (Decker et al., 2012). Choosing ERA-Interim short-term forecasts is motivated by the higher temporal resolution compared to the 6hourly re-analysis product that is not sufficient for resolving all wind speed maxima during the day (Fiedler et al., 2013). Statistics of the near-surface wind speed from these short-term forecasts are found to be close to the 6-hourly reanalysis of ERA-Interim (Fiedler et al., 2013).

Preferential dust sources are prescribed using the dust source activation frequency (DSAF) map derived from satellite observations (Schepanski et al., 2007, 2009). A source is defined as a region where at least two dust emission events are detected between March 2006 and February 2008 as in Fiedler et al. (2013). Depending on surface properties like vegetation fraction, soil moisture and roughness length, dust emission occurs in these sources when the particle-sizedependent threshold of the $10 \mathrm{~m}$ wind speed is exceeded (for details see Marticorena and Bergametti, 1995; Tegen et al., 2002). Soil moisture has to be below $0.28 \mathrm{~m}^{3} \mathrm{~m}^{-3}$, the field capacity assumed for silt and clay soil types. An experiment without soil moisture is run to estimate the effect of water in the topsoil on dust emission.

Calculating the dust emission associated with depressions and cyclones requires the definition of an area affected by associated peak winds. The tracking algorithm determines an area for the grid boxes lying within the outermost closed contour of the geopotential height at $925 \mathrm{hPa}$ at midnight. This centre area is used for analysing the track density per season (Sects. 3.1 and 3.2). Dust emission, however, may occur in an area larger than the centre, e.g. near the fronts. In 
a) $20-02-2013,16$ UTC

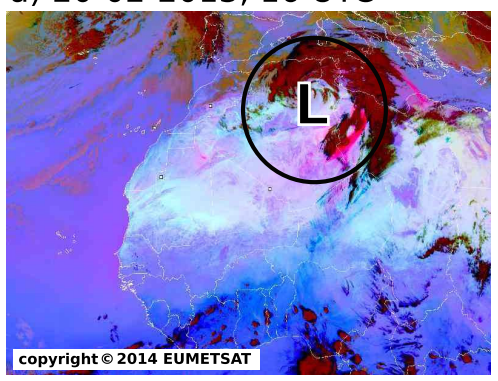

b) $09-03-2012,15$ UTC

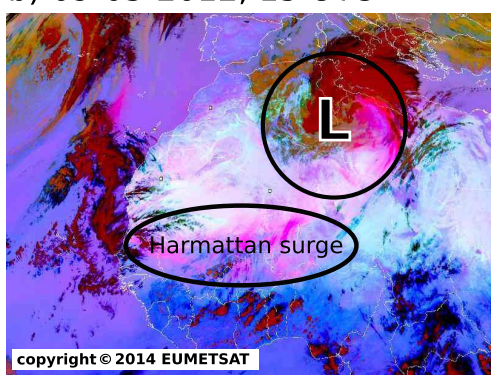

c) $05-04-2011,15$ UTC

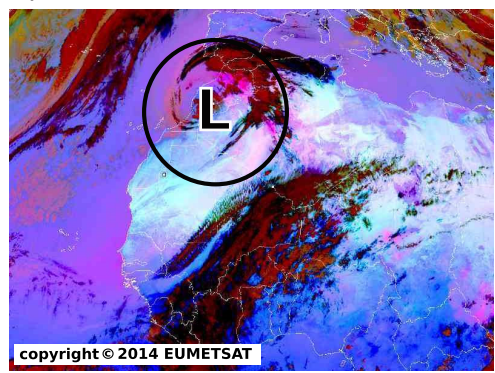

Figure 1. Observations of cyclones and associated dust aerosol over North Africa. Shown are false-colour images from MSG-SEVIRI (e.g. Schepanski et al., 2007) indicating mineral dust aerosol (pink) and clouds (red and black). Circles and ellipse mark the cyclone-affected area with a radius of $10^{\circ}$ and dust emission associated with a Harmattan surge, respectively.

order to include these dust emissions in the climatology, a cyclone-affected area is approximated by a circle around the identified minimum in the geopotential height. This area is calculated at midnight and used for selecting the 3-hourly dust emission associated with the depression or cyclone between 15:00 UTC of the previous day and 12:00 UTC of the same day (Sects. 3.5 and 3.6). The radius of this circle is set to $10^{\circ}$, a value corresponding to a latitudinal distance of $964 \mathrm{~km}$ at $30^{\circ} \mathrm{N}$. The choice of $10^{\circ}$ is motivated by previous studies (e.g. Bou Karam et al., 2010) and tested by sensitivity experiments. These show that even when the radius of the circle is doubled, the spatial pattern of the fraction of dust emission associated with cyclones shown in Sect. 3.6 is robust.

Figure 1 shows the cyclone-affected area and false colour images derived from thermal and infrared radiation measurements from the "Spinning Enhanced Visible and Infrared Imager" (SEVIRI) of the geostationary Meteosat Second Generation (MSG) satellite (e.g. Schepanski et al., 2007, 2009). The DSAF of this satellite product for March 2006 to February 2010 (Schepanski et al., 2007, 2009, 2012) is used for validating the dust emission calculation. The typical horizontal extent of these cyclones, visible by the curling cloud band (red) and indicated by a circle around the cyclone centre, is of the order of $10^{\circ}$. Dust aerosol is visible near the cloud band, but parts of it is likely obscured by clouds. At 9 March 2012, dust emission also occurs over southern West Africa (Fig. 1b), highlighted by an ellipse. These emissions are not directly related to the cyclone but likely driven by a Harmattan surge associated with the post frontal ridge (e.g. Knippertz and Fink, 2006; Knippertz and Todd, 2012, and references therein).

\section{Results}

\subsection{Climatology of depressions}

Figure 2 shows the seasonally averaged occurrence frequency of depressions identified by the algorithm. In winter,
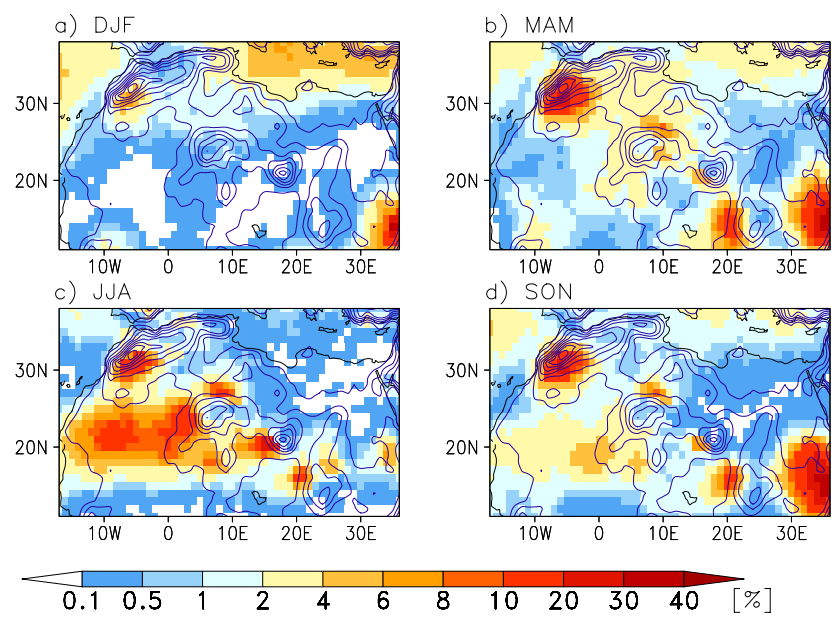

Figure 2. Track density of all identified depressions. Climatology of the occurrence frequency of depressions for (a) DecemberFebruary, (b) March-May, (c) June-August and (d) SeptemberNovember for 1989-2008 based on the depression centre defined by the outermost closed contour in the geopotential height at $925 \mathrm{hPa}$ from the tracking algorithm (Sect. 2.1). Contours show the orography in steps of $200 \mathrm{~m}$.

depressions are found over the Mediterranean basin during $4 \%$ of the time (Fig. 2a) corresponding to up to five depressions per winter. Maxima of similarly large depression occurrence frequencies lie to the south of the High Atlas and to the west of the Ethiopian Highlands (see Fig. 5 for geographical terms). The origin of these depressions may be partly related to lee troughs that are associated with closed contours in the geopotential height at $925 \mathrm{hPa}$. In the case of the Ethiopian Highlands, the heat low that is located here during winter (Lavaysse et al., 2009) may explain another large portion of identified depressions. The general location of depressions over the Mediterranean Sea and the lee maximum of the Atlas Mountains are in agreement with previous studies (Trigo et al., 1999; Maheras et al., 2001). The exact number and location of occurence maxima, however, depend 
a)

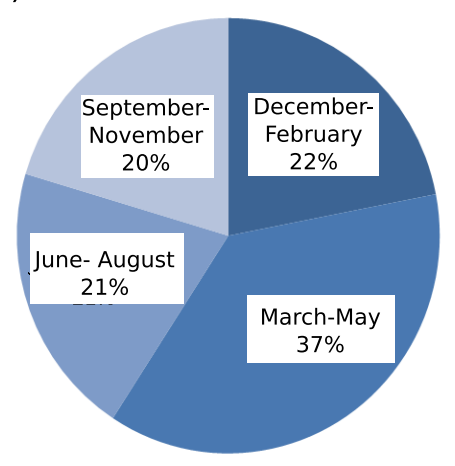

b)

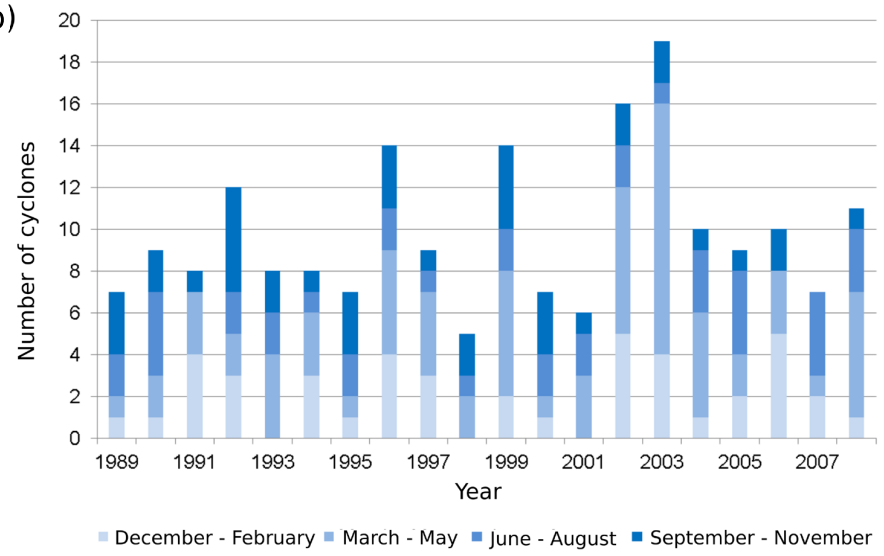

Figure 3. Seasonal and interannual variations of long-lived and migrating cyclones. (a) Seasonal distribution of cyclones and (b) time series of cyclones in the sub-domain $0-40^{\circ} \mathrm{N}$ and $20^{\circ} \mathrm{W}-45^{\circ} \mathrm{E}$ for $1989-2008$.

on the underlying data set and identification technique (e.g. Maheras et al., 2001; Hannachi et al., 2011; Hodges et al., 2011, and references therein).

Depressions over the continent in spring are generally more frequent than in winter (Fig. 2b). The maximum south of the High Atlas dominates the climatology in the north with occurrence frequencies of up to $30 \%$ corresponding to ten depressions per spring. A secondary maximum can be identified at the northern side of the Hoggar Mountains with an occurrence frequency of up to $8 \%$. These two maxima agree with the formation of springtime cyclones from the literature, although the exact locations and frequencies differ (Maheras et al., 2001; Hannachi et al., 2011). Other studies for springtime North Africa find a single maximum for depressions (Trigo et al., 1999). Reasons for these differences are the choice of a different data basis, time period, identification method, as well as the time of day due to the influence of the diurnal cycle of the net radiation budget on heat lows (Maheras et al., 2001). Further maxima that can be related to lee troughs are found southwest of all mountains in the central Sahara due to the prevailing northeasterly Harmattan winds during this season. Maxima of the occurrence frequency in the vicinity of the Ethiopian Highlands and the Ennedi Mountains are, herein, particularly large with around $20 \%$.

Between June and August, occurrence frequencies of up to $20 \%$ are found over West Africa (Fig. 2c). Here, the Saharan heat low dominates the climatology while AEWs regularly influence the meteorological conditions (Lavaysse et al., 2009; Thorncroft and Hodges, 2000; Luo et al., 2004). Particularly the atmospheric depressions close to and offshore of the West African coast point to the presence of AEWs. Similar track densities are found in the vicinity of mountains where the Saharan heat low influences the occurrence of depressions, predominantly at the Hoggar Massif (Lavaysse et al., 2009).
The heat low over West Africa and the maxima near mountains in the central Sahara are also present in autumn but the relative importance changes (Fig. 2d). In autumn, the frequency of depressions west of the Ethiopian Highlands is larger with up to $30 \%$, while the values over West Africa decrease to less than $6 \%$. This pattern is coherent with the shift of the heat low from West Africa towards the southeast near the equator (Lavaysse et al., 2009). Heat lows and depressions in the vicinity of mountains seem to dominate the climatology of depressions throughout the year. Migrating cyclones and surface signatures of AEWs are investigated in the next section.

\subsection{Climatology of cyclones}

Migrating cyclones and surface signatures of AEWs are filtered as described in Sect. 2.1. The term cyclone is used for both types in the following. Cyclones regularly form over North Africa and the Mediterranean region, but the number of events is substantially smaller than the number of depressions. In the annual mean, 10 cyclones occur in the subdomain investigated, namely 0 to $40^{\circ} \mathrm{N}$ and $20^{\circ} \mathrm{W}$ to $45^{\circ} \mathrm{E}$. Figure $3 \mathrm{a}$ shows the seasonal fraction of the total number of 196 cyclones that pass the filter. The analysis reveals that most of the cyclones form between March and May with $37 \%$. The remaining seasons have fewer events with roughly $20 \%$ each.

The time series of the total number of cyclones per year is shown in Fig. 3b. The year-to-year variability of cyclone activity is relatively large with a factor of three to four. The years with most identified events are 2003 with 19 cyclones, followed by 2002 with 16, and 1996 and 1999 with 14 events each. The most inactive years are 1998, 2000, 2001 and 2007 with five to seven cyclones each. Most of this variability can be explained by the cyclone activity during spring. The yearto-year variability for this season is particularly large. Years with a large event number experience 6-12 cyclones, while 
years with low activity have one to three events between March and May.

Figure 4 shows the seasonal distribution of cyclone occurrence frequency in the 20-year period. The dominant cyclone track between December and February stretches from the Aegean Sea to Cyprus (Fig. 4a). Some areas in this track have occurrence frequencies of up to $0.8 \%$ corresponding to one cyclone every second year. Including filling cyclones doubles the number of cyclones passing the eastern Mediterranean (not shown). Few cyclones are situated over the African continent during winter. A maximum cyclone frequency of $0.4 \%$ is limited to areas along the northern coast between Tunis, Tunisia, and Tobruk, Libya. Similar values are found north of the Great Eastern Erg, the southeastern side of the Tell Atlas, Algeria and Tunisia, north of the Hoggar Mountains, Algeria, and south of the High Atlas Range, Morocco.

Between March and May, cyclones occur most frequently over North Africa (Fig. 4b). Cyclones at the southern side of the High Atlas are identified in up to $0.5 \%$ of the time between 1989 and 2008. Cyclones over areas of the Great Eastern Erg between the Tell Atlas Mountains and the Hoggar Massif, Tunisia and Algeria occur in up to $0.8 \%$ of the time. This cyclone frequency is comparable to the cyclone track in the wintertime Mediterranean Sea (Fig. 4a-b). The eastern side of the Al-Hamra Plateau, Libya, also shows a frequency around $0.8 \%$, which is consistent with the reported ideal conditions in this region (Alpert et al., 1990; Pedgley, 1972).

The peak cyclone activity north of $25^{\circ} \mathrm{N}$ in winter and spring rapidly decreases as the year progresses (Fig. 4c). Maxima of the track density are shifted from the north to West Africa where cyclones occur in up to $0.6 \%$ of the time. These occur primarily over Mali and Mauritania around $20^{\circ} \mathrm{N}$, a region known for frequent occurrence of AEW signatures at higher altitudes (Thorncroft and Hodges, 2000; Mekonnen et al., 2006). Here, the cyclones are connected to AEWs that are strong enough to form a signature near the surface. Agusti-Panareda et al. (2010) suggest that AEWs are too weak in the ECMWF model over the eastern North Atlantic. This could imply that fewer AEWs are strong enough to be detected with the tracking algorithm used here. It is interesting that the track density peaks in the lee of mountains similar to the springtime maximum in the north. These maxima are situated at the western sides of the Tibesti, Aïr, and Adrar des Iforas Mountains. The location suggests that the interaction of the flow with mountains aid the deepening and formation of closed contours in the geopotential height at $925 \mathrm{hPa}$. This result is in agreement with Bou Karam et al. (2009) who show that vortices form in the lee of mountain barriers during summer. Autumn shows the smallest cyclone activity with occurrence frequencies below $0.3 \%$ (Fig. 4d). The regions of most frequent cyclone occurrence are summarized in Fig. 5. These are the northern fringes of North Africa between December and May and West Africa from June to August. The characteristics of the cyclones are investigated in the following.
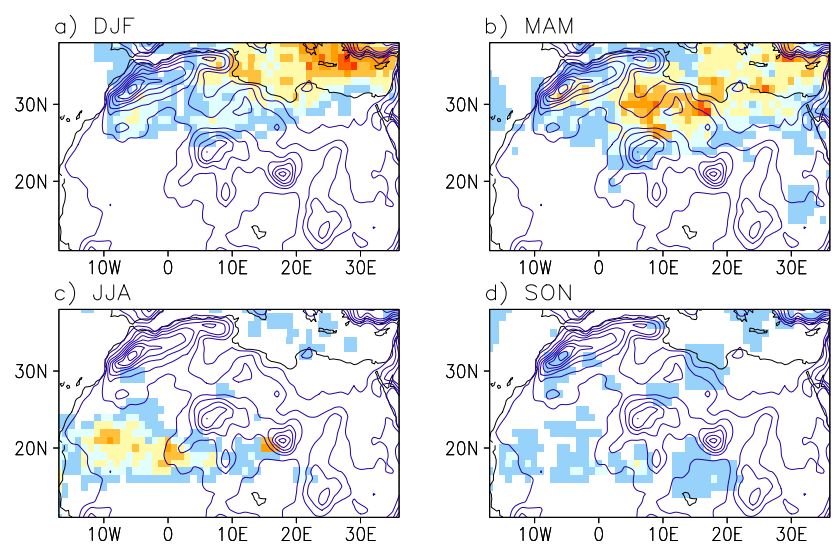

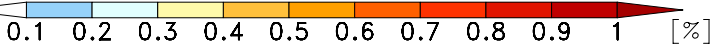

Figure 4. Track density of long-lived and migrating cyclones. Climatology of the occurrence frequency of cyclones for (a) December-February, (b) March-May, (c) June-August, and (d) September-November for 1989-2008 based on the cyclone centre defined by the outermost closed contour in the geopotential height at $925 \mathrm{hPa}$ from the tracking algorithm (Sect. 2.1). Contours show the orography in steps of $200 \mathrm{~m}$.

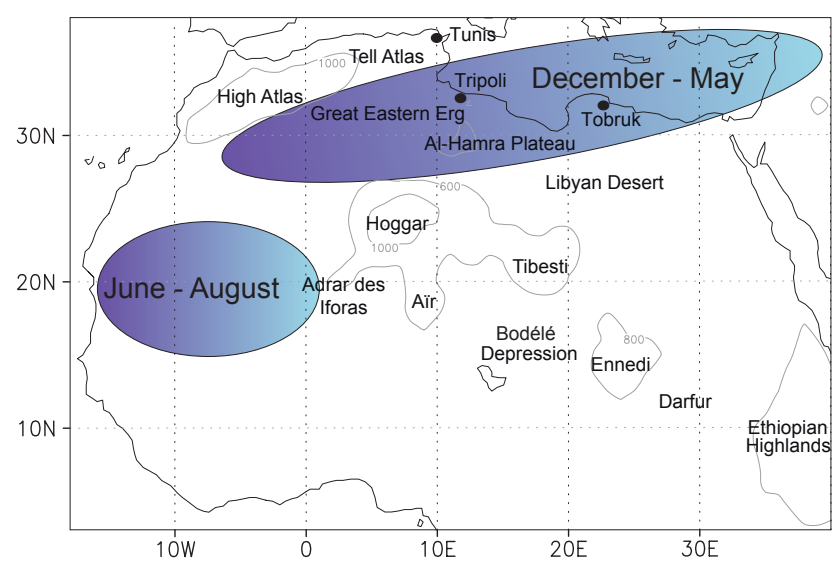

Figure 5. Schematic overview on regions of most frequent cyclone occurrence. Contours show the orography based on ERA-Interim. Geographical terms used in the text are indicated.

\subsection{Characteristics of cyclones}

Figure 6 shows the life time and zonal displacement of the identified cyclones for areas north and south of $20^{\circ} \mathrm{N}$ over the continent. In the north, cyclogenesis occurs 56 times during the 20-year period, more than half of which form between March and May (32 cyclones). Most of these cyclones have their origin in the vicinity of the Atlas Mountains with $26 \mathrm{cy}-$ clones between $15^{\circ} \mathrm{W}$ and $10^{\circ} \mathrm{E}$. Cyclones in the north frequently live for 3 days in spring (Fig. 6a). Life times between 5 and 7 days are similarly common for the season. Springtime cyclones predominantly follow eastward tracks in the north (Fig. 6c). The migration distance is most often $30^{\circ}$ to 
the east, closely followed by 20 and $10^{\circ}$. Some cyclones with eastward trajectories also form south of $20^{\circ} \mathrm{N}$ during spring (Fig. 6d). Wintertime cyclones have a similar distribution of the migration direction. The prevailing eastward migration in the north is in agreement with previous studies (e.g. Alpert et al., 1990; Hannachi et al., 2011).

South of $20^{\circ} \mathrm{N}$, the seasonality of cyclogenesis is different. Out of 50 cyclones forming here in total, $36 \%$ occur between June and August followed by 26 and $28 \%$ in autumn and spring, respectively. Figure $6 \mathrm{~b}$ shows the cyclone life time for the south. Here, the majority of cyclones are identified over three to four days. Summertime cyclones also live frequently for six days. The prevailing migration direction during summer and autumn is westwards by mostly 20 $30^{\circ}$ (Fig. 6d) that is consistent with the propagation of AEWs (Burpee, 1972; Thorncroft and Hodges, 2000).

\subsection{Climatology of dust emission}

Before combining the atmospheric depressions and cyclones with dust emission, the latter is validated against a satellite product. Unfortunately, a quantitative estimate for the emitted mass is currently unavailable from long-term observations over North Africa. As an alternative, the DSAF from satellite observations (Schepanski et al., 2007, 2009, 2012) is used for a qualitative comparison of the number of dust emission events from the dust emission calculation for the period March 2006 to February 2010. Simulated dust emission events with fluxes exceeding $10^{-5} \mathrm{~g} \mathrm{~m}^{-2} \mathrm{~s}^{-1}$ are taken into account only, as small amounts are unlikely to be detected by the instrument (Laurent et al., 2010).

Figure 7 shows the annual mean DSAF derived from satellite observations and from the dust emission calculation with meteorological fields from ERA-Interim. The DSAFs below $5 \%$ compare well against the model simulation over large areas in the central Sahara. Maxima between the Hoggar and the Tibesti Mountains as well as over the Bodélé Depression with up to $35 \%$ activation frequency are also well represented. Comparison to ground-based measurements in the Bodélé Depression has also shown a good agreement of the time and intensity of dust emission from this area (Fiedler et al., 2013). However, the high DSAFs from the model at the western coast of the continent are not seen in the satellite product (Fig. 7). During spring and summer, the western coast may be influenced by moist air advected from the Atlantic, which can prevent dust detection in the satellite product (Brindley et al., 2012), although the visual identification by Schepanski et al. (2012) might be less influenced by moisture than an automatic algorithm (Ashpole and Washington, 2013). Also the tendency to larger DSAF over the north compared to the south in the model simulation is not in agreement with the satellite DSAF. In winter and spring clouds associated with cyclones may obscure parts of the dust emission in observations along the northern margins of the desert (Fig. 1), previously indicated by Schepanski et al. (2009). It
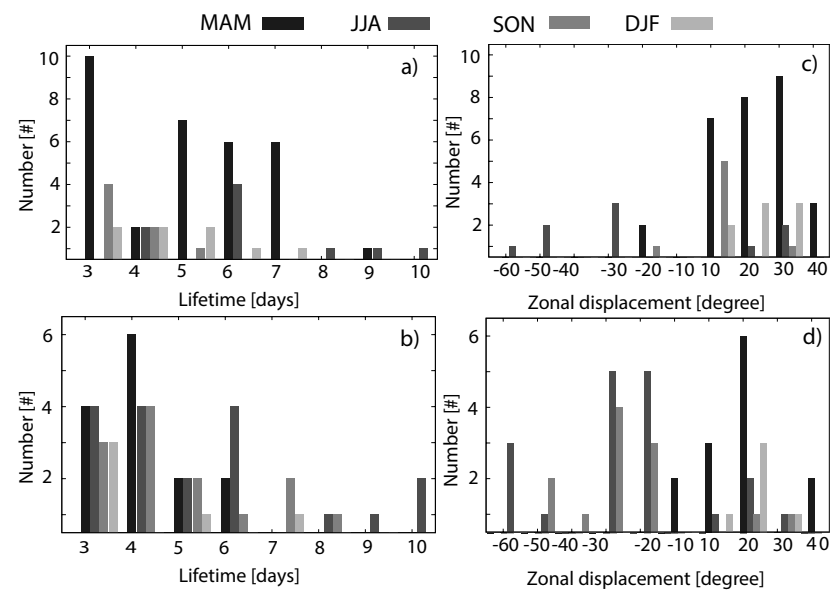

Figure 6. Histograms of characteristics from long-lived and migrating cyclones. Cyclone life times for 1989-2008 forming (a) in the north $\left(15^{\circ} \mathrm{W}-35^{\circ} \mathrm{E}, 20-32^{\circ} \mathrm{N}\right)$, and $(\mathbf{b})$ in the south $\left(15^{\circ} \mathrm{W}-35^{\circ} \mathrm{E}\right.$, $0-20^{\circ} \mathrm{N}$ ); and zonal displacement of cyclone centres during their life time forming (c) in the north, and (d) in the south.

is important to highlight that these differences of DSAF do not allow a conclusion on the quality of the dust emission amount. The model can have higher DSAFs, but these events could be weaker than the detected source activations, and vice versa (Tegen et al., 2013). From the perspective of dust modelling, quantitative estimates of the emission amount from observation would be useful. The dust emission amount is used in the following sections to estimate the relative importance of atmospheric depressions and cyclones for North African emission.

\subsection{Dust emission associated with depressions}

Figure 8 shows the year-to-year variability of the annual total of dust emission integrated over North Africa. The annual total emission varies between 350 and $500 \mathrm{Tg}$ per year. A substantial amount of these emissions occur during spring with a total between 100 and $250 \mathrm{Tg}$ per year. Atmospheric depressions are associated with total emission amounts of typically 200-300 Tg per year. Annually and spatially averaged across dust sources of North Africa, $55 \%$ of the dust emission is associated with atmospheric depressions. Regionally even larger fractions of dust emission coincide with depressions shown along with the occurrence frequency of depressions in Fig. 9. Particularly areas in northern and western Africa have dust emission associated with depressions of up to $80 \%$. Since the influence of depressions on dust emission is limited to a radius of $10^{\circ}$ (Sect. 2), nearby maxima of the depression occurrence frequency can be associated with them. For instance, the large dust emission amounts associated with depressions in the north and also close to the Ethiopian Highlands are associated with maxima in occurrence frequency. In contrast, dust emission in the northeast and west coincide 


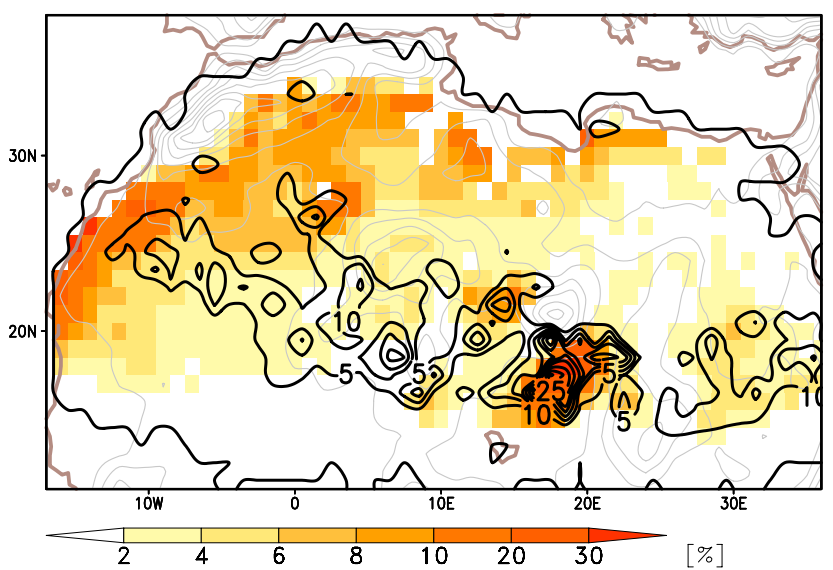

Figure 7. Dust source activation frequency based on satellite observations and ERA-Interim data. The dust source activation frequency (DSAF) is the number of dust emission events per time. Shown is the annual mean DSAF derived from SEVIRI satellite observations by Schepanski et al. $(2007,2012)$ in steps of $5 \%$ (black contours) and based on the dust emission model by Tegen et al. (2002) driven by the near-surface wind speed and soil moisture from 3 hourly ERA-Interim forecasts (shaded). Dust emission events larger than $10^{-5} \mathrm{~g} \mathrm{~m}^{-2} \mathrm{~s}^{-1}$ are considered from the dust model only, as smaller dust amounts are unlikely to be detected in the satellite product (Laurent et al., 2010). The time period considered is March 2006 to February 2010 following the satellite observation. Grey contours show the orography in steps of $200 \mathrm{~m}$.

with few depressions, suggesting that these events are particularly intense.

The seasonal distribution of the dust emission fraction associated with atmospheric depressions is shown in Fig. 10. Depressions coincide with $50 \%$ of the dust emission in winter over most of North Africa (Fig. 10a). Larger fractions are associated with depressions in Libya, Tunisia and Sudan with values of up to $80 \%$. These maxima coincide with the frequent formation of depressions over the Mediterranean region and in the lee of the Ethiopian Highlands. The frequent formation close to the High Atlas is not associated with a dust emission maximum, suggesting weak winds over the potential dust sources in winter. The large fractions of dust emission in West Sahara occur away from a location with frequent depression formation, pointing to rare but strong depressions. Spring shows even larger dust emission associated with depressions in wide areas to the north of $25^{\circ} \mathrm{N}$ and west of $10^{\circ} \mathrm{E}$ with up to $90 \%$ (Fig. 10b). These areas lie within or close to regions where depressions frequently form. Integrated over the entire of North Africa, emission associated with depressions in spring has values of $80-150 \mathrm{Tg}$ per year (Fig. 8).

Atmospheric depressions in summer are associated with up to $90 \%$ of the dust emission across most of North Africa (Fig. 10c). Depressions are abundant in this season (Sect. 3.1). Most of them, particularly over West Africa, are

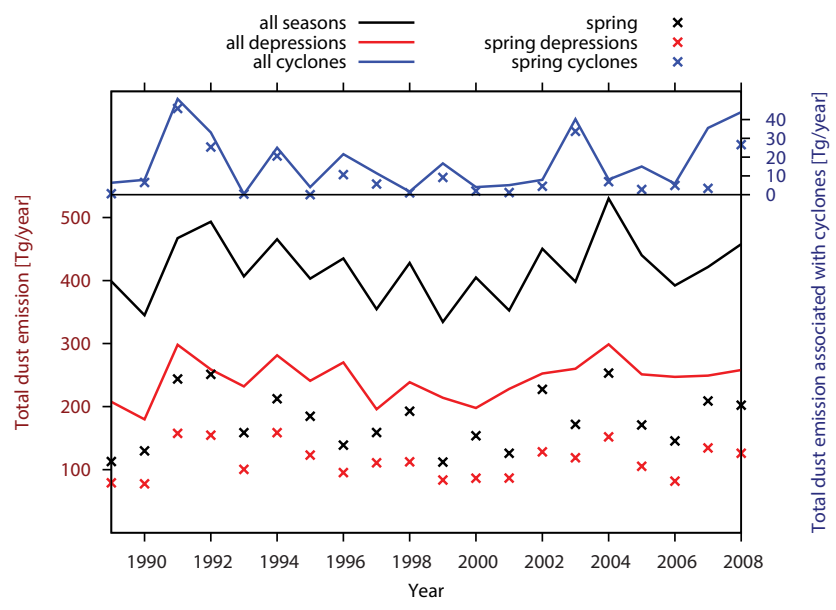

Figure 8. Time series of total dust emissions. Shown are dust emission per year as total amounts for (black) all processes (lines) in all seasons and (crosses) in spring for 1989-2008. Red shows emission totals associated with atmospheric depressions and blue emission totals associated with long-lived and migrating cyclones. All values are integrated over the entire of North Africa.

likely Saharan heat lows given the spatio-temporal agreement with the climatology by Lavaysse et al. (2009). Areas of their frequent formation enclose most of the dust emission coinciding with them. In autumn, similarly large values are found along the northern and western margins of the continent, west of the Hoggar Massif and west of the Ethiopian Highlands (Fig. 10d). The frequent formation of depressions within a radius of $10^{\circ}$ coincides with these maxima. This large and widespread agreement between dust emission and depressions in summer is surprising as other dust-emitting processes have been suggested in the literature (e.g. Fiedler et al., 2013; Heinold et al., 2013) and shall be briefly discussed here.

Estimating the dust emission amount associated with the heat low likely involves a number of mechanisms. Emissions can be directly caused by the horizontal pressure gradient around the heat low, but this alone may not always be sufficient to cause substantial dust mobilization. Midmorning winds can be enhanced through the NLLJ mechanism (Fiedler et al., 2013), which depends on the horizontal pressure gradient around the heat low and the diurnal evolution of the boundary layer. Using the NLLJ identification method from Fiedler et al. (2013) to estimate the amount of dust emission associated with NLLJs within depressions results in an annual and spatial average of $12 \%$. Between March and October 12-16\% of the dust emission is associated with both phenomena, while values are below $10 \%$ during the rest of the year (not shown). This result is in agreement with Fiedler et al. (2013) who show a frequent NLLJ formation along the margins of the Saharan heat low. Another process potentially embedded in depressions are haboobs, which are presumably not well represented in ERA-Interim 


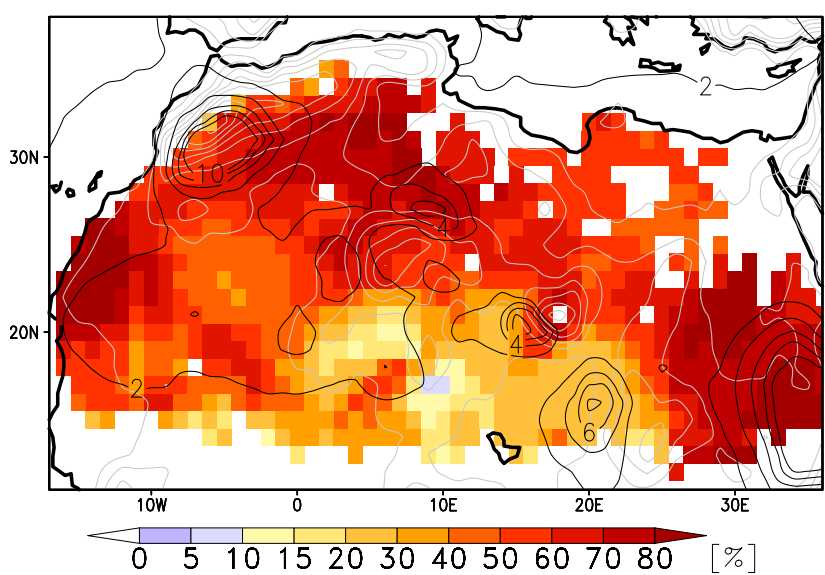

Figure 9. Annual fraction of dust emission amounts associated with atmospheric depressions. Shown is the fraction of total dust emission associated with depressions in percent averaged for 1989-2008 (shaded). Dust emission within a radius of $10^{\circ}$ from the depression centre is considered (Sect. 2). Black contours show the annually averaged occurrence frequency of depressions in steps of $2 \%$. Grey contours show the orography in steps of $200 \mathrm{~m}$.

data due to the physical parameterization of moist convection. Dust emission coinciding with NLLJs and haboobs can also occur along with mobile and long-lived depressions. These are termed cyclones in the following and will be investigated next.

\subsection{Dust emission associated with cyclones}

Integrating dust emission associated with mobile and longlived cyclones illustrates that the total emission amount is comparably small with maxima around $40 \mathrm{Tg}$ per year (Fig. 8). The majority of emissions associated with cyclones is found in spring pointing to the importance of cyclones over northern areas of the continent (Fig. 4). The temporal evolution of the emission does not correlate well with the number of cyclones (Figs. 3 and 8) with a correlation coefficient of 0.35 and 0.43 for annual and spring values, respectively. This is due to different influences that determine the total emission amount associated with cyclones. Relevant factors are the intensity of emission, the proximity of the cyclone to potential dust sources and the cyclone type. These aspects are analysed in the following sections beginning with the spatial distributions of associated dust emission.

\subsubsection{Seasonal climatology}

The emission amount associated with migrating cyclones is shown first followed by the presentation of the fraction of the total dust emission associated with cyclones. Figure 11 shows the seasonal total of dust emission and the number of intense emission events associated with cyclones averaged over the 20-year period. Intense emission is defined for fluxes greater than $10^{-5} \mathrm{~g} \mathrm{~m}^{-2} \mathrm{~s}^{-1}$ follow-
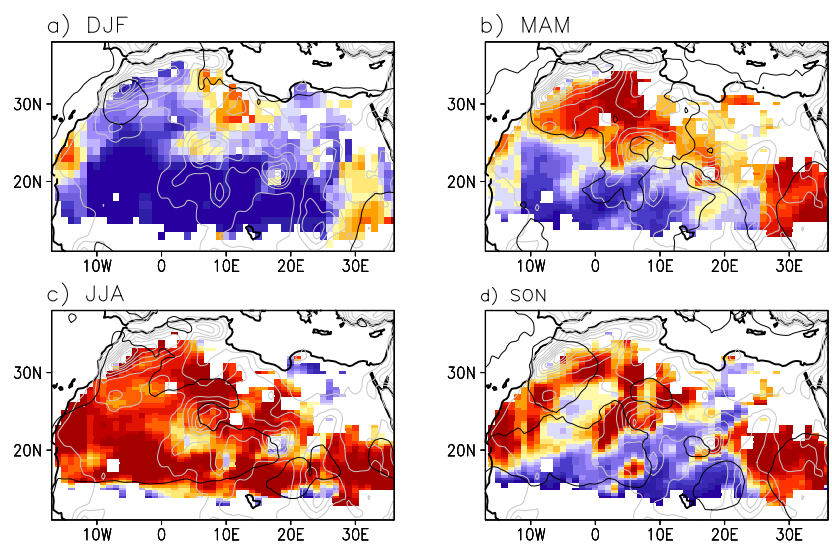

01015202530354045505560657075808590 [\%]

Figure 10. Seasonal fraction of dust emission amount associated with atmospheric depressions. Shown are fractions of total dust emission associated with depressions in percent for (a) DecemberFebruary, (b) March-May, (c) June-August and (d) SeptemberNovember averaged for 1989-2008 (shaded). Dust emission within a radius of $10^{\circ}$ from the depression centre is considered (Sect. 2). Areas within the black contour have an occurrence frequency of depression of more than $2 \%$ (Fig. 2). Grey contours show the orography in steps of $200 \mathrm{~m}$.

ing Laurent et al. (2010). Across the continent and throughout the year, the seasonal total of dust emission within the cyclone-affected area (Sect. 2.2) is most frequently less than $1 \mathrm{~g} \mathrm{~m}^{-2}$. Single regions and seasons, however, show distinct maxima of dust emission of up to $10 \mathrm{~g} \mathrm{~m}^{-2}$ north of $20^{\circ} \mathrm{N}$. Between December and February, peak emissions near the Atlas and Hoggar Mountains as well as in Libya are 2$4 \mathrm{~g} \mathrm{~m}^{-2}$ (Fig. 11a). Areas with more than three intense emission events per season lie mostly away from dust emission maxima. This points to moderate but frequent dust emissions in winter maxima, while rather small total emissions in some regions are generated by a few intense events.

Springtime dust emission of $4-10 \mathrm{~g} \mathrm{~m}^{-2}$ associated with cyclones occur over a wider area (Fig. 11b). The overall largest dust emission associated with cyclones are found in this season. Cyclones are particularly frequent then due to the large temperature contrast between land and sea which favours their development. Peak emissions coinciding with cyclones are found south of the Atlas Mountains, and west of the Libyan desert. More than three intense emission events occur over most of the region north of $20^{\circ} \mathrm{N}$. Maxima of the emission amount coincide with more than six, in some areas even nine, intense emission events. This suggests that intense events substantially contribute to the largest emission amounts associated with springtime cyclones.

The findings change dramatically in summer when maximum emissions associated with cyclones are situated over West Africa with up to $6 \mathrm{~g} \mathrm{~m}^{-2}$ (Fig. 11c) coinciding with more than six intense emission events. Here, surface 

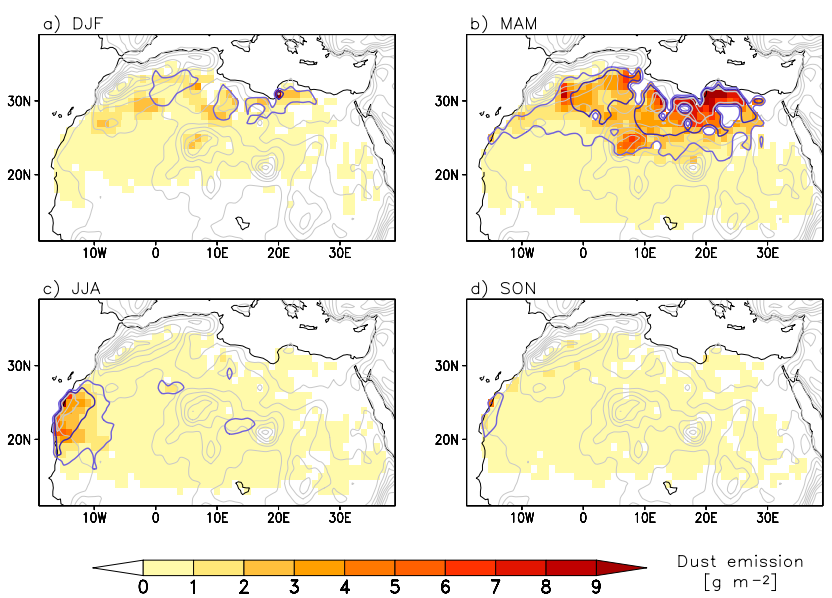

Figure 11. Seasonal dust emission associated with long-lived and migrating cyclones. Shown are mean emissions (shaded) for (a) December-February, (b) March-May, (c) June-August and (d) September-November averaged for 1989-2008. Blue contours show the number of intense dust emission events, defined by a flux larger than $10^{-5} \mathrm{~g} \mathrm{~m}^{-2} \mathrm{~s}^{-1}$ following Laurent et al. (2010), in steps of three events. Grey contours show the orography in steps of $200 \mathrm{~m}$.

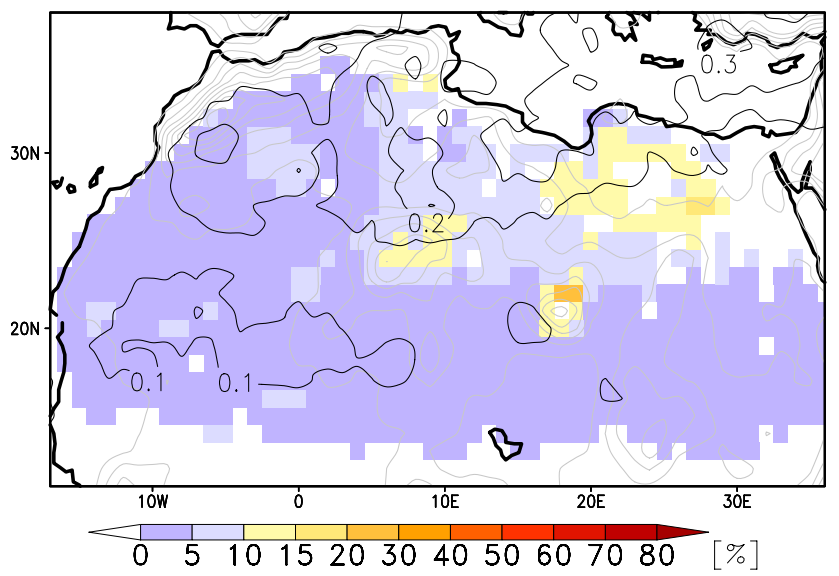

Figure 12. Annual fraction of dust emission amount associated with long-lived and migrating cyclones. Shown is the fraction of total dust emission associated with cyclones in percent averaged for 1989-2008 (shaded). Dust emission within a radius of $10^{\circ}$ from the cyclone centre is considered (see Sect. 2). Black contours show the annually averaged occurrence frequency of cyclones in steps of 0.1 percent. Grey contours show the orography in steps of $200 \mathrm{~m}$.

signatures of AEWs may be deepest and cause the highest wind speeds (e.g. Thorncroft and Hodges, 2000). The coastal effect may be a contributing factor for strong winds in this region. In autumn, the number of intense emissions in the west is smaller with three events and the total dust emission associated with cyclones is smallest with typically less than $1 \mathrm{~g} \mathrm{~m}^{-2}$ (Fig. 11d). This is in agreement with few cyclones identified for this season.
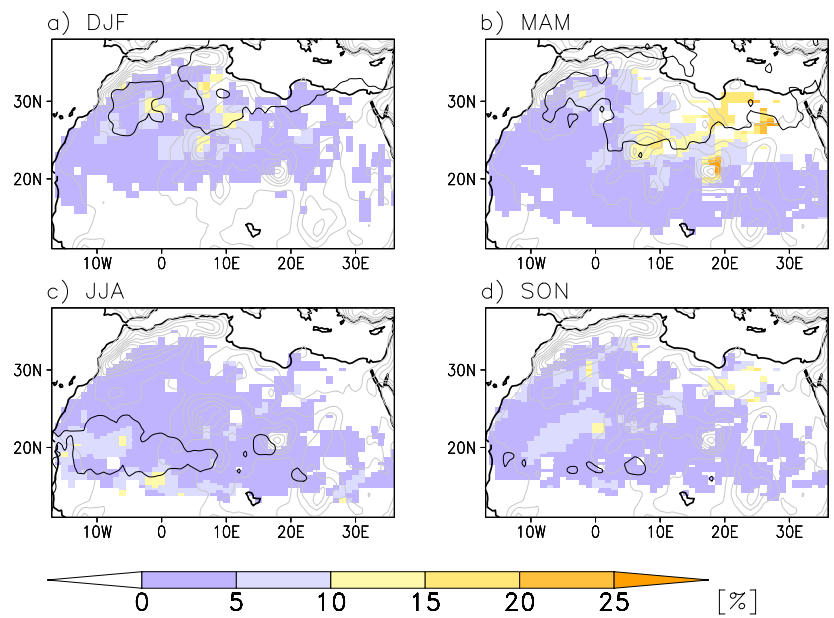

Figure 13. Seasonal fraction of dust emission amount associated with long-lived and migrating cyclones. Shown are fractions of total dust emission associated with depressions in percent for (a) December-February, (b) March-May, (c) June-August and (d) September-November averaged for 1989-2008 (shaded). Dust emission within a radius of $10^{\circ}$ from the cyclone centre is considered (Sect. 2). Areas within the black contour have an occurrence frequency of depression of more than $0.2 \%$ (Fig. 2). Grey contours show the orography in steps of $200 \mathrm{~m}$.

The fraction of the dust emission associated with migrating and long-lived cyclones relative to the total amount emitted per year is $4 \%$ annually and spatially averaged over dust sources. Figure 12 shows the spatial distribution of these fractions and the occurrence frequency of cyclones annually averaged. Single regions in the northeast have dust emission associated with cyclones exceeding $10 \%$. These regions are close to areas where cyclones occur most frequently.

The dust emission fraction is larger regionally in single seasons which are shown in Fig. 13. From December to February, substantial dust emission fractions associated with cyclones occur in areas north of $20^{\circ} \mathrm{N}$ only, because of the limitation of cyclone tracks to northern locations (Fig. 13a). The largest dust emission amounts associated with cyclones reach values of $5-15 \%$ between $15^{\circ} \mathrm{W}$ and $15^{\circ} \mathrm{E}$. Cyclones tracking over the eastern Mediterranean Sea in winter are not associated with large amounts of North African dust emission indicated by dust emission fractions below $5 \%$ in regions east of $15^{\circ} \mathrm{E}$. In spring, however, larger dust emissions of 10-25\% are associated with cyclones in this region (Fig. 13b) when the main cyclone track shifts southwards onto the continent (Fig. 4b). This is the overall largest area and magnitude of dust emission coinciding with cyclones in North Africa. Smaller areas with similar springtime fractions of dust emission lie to the south of the Atlas Mountains, northeast of the Hoggar Massif and in the Tibesti Mountains. These are within a distance of $10^{\circ}$ from the areas of most frequent cyclone presence. 
Between June and August, dust emission fractions in regions north of $25^{\circ} \mathrm{N}$ drop to values below $5 \%$ while cyclones in parts of Mali and Mauritania are associated with 5-15\% of the dust emission amount (Fig. 13c). Over West Africa, surface signatures of AEWs occur along $20^{\circ} \mathrm{N}$ and enclose these maxima of the dust emission fraction. Dust emission associated with cyclones remain similar in autumn but the spatial location of maxima changes (Fig. 13d). The highest values of around $15 \%$, now, occur in the centre of the Sahara, the Western Great Erg and the Libyan Desert (Fig. 13c-d). These are situated away from areas of frequent cyclone passage suggesting that rare events are associated with relatively strong emission. It is, however, important to underline that the dust emission connected to cyclones is relatively small in autumn with typical values below $1 \mathrm{~g} \mathrm{~m}^{-2}$. This implies that, even though the relative importance is comparable to the north in winter and spring, the importance in terms of total dust mass is smaller (Fig. 11d).

In light of the large relative importance of depressions for dust emission (Sect. 3.5), the overall fraction associated with migrating cyclones is small. Springtime depressions are associated with up to $90 \%$ of dust emission in the lee of the High Atlas but considering mobile cyclones as a sub-class of depressions changes the fraction of dust emission to less than $15 \%$ (compare Figs. 10b and 13b). Over Libya, springtime dust emission associated with depressions are with values around $50 \%$ also larger than the ones with cyclones with maxima around $25 \%$. Particularly in the lee of the Atlas Mountains the dust emission associated with cyclones is six times smaller than the amount associated with depressions. A reduction of dust emission is expected in the climatology with cyclones as a sub-class of depression. The High Atlas is the region where lee depressions may lead to cyclogenesis. The present results, however, indicate that only a few of these lee depressions develop into migrating and longlived cyclones. There are also no large and widespread dust emissions associated with surface signatures of AEWs during summer. This result gives evidence that most of the dust emitted in summertime depressions is due to the frequent occurrence of heat lows over West Africa.

\subsubsection{Dependency on cyclone quadrant}

The areas of largest dust emission amounts associated with cyclones reside close to maxima of cyclone tracks (Sect. 3.2). However, maxima of cyclones and dust emission (Figs. 4 and 13) do not match perfectly due to two factors. On the one hand the location of peak winds within the cyclone-affected area is often away from the actual centre. On the other hand the parameterization of dust sources restricts the region of active emission within the cyclone-affected area. The map of potential dust sources enables dust emission in most areas of North Africa so that the location of peak winds is expected to be the dominant factor. The spatial distribution of the dust emission within the cyclone-affected area is inves-

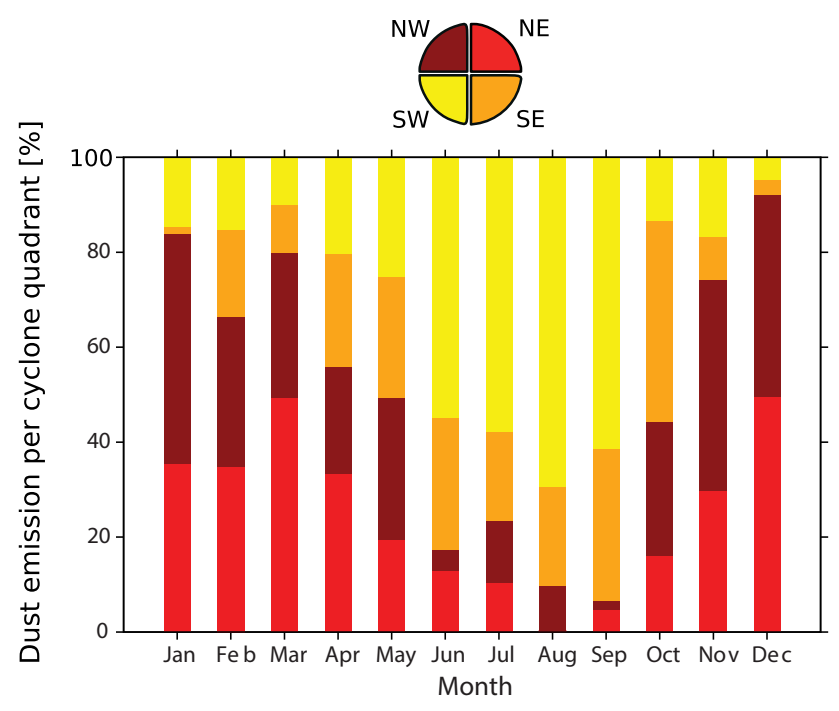

Figure 14. Monthly fraction of dust emission from the four quadrants of long-lived and migrating cyclones averaged for the northern sub-domain $\left(15^{\circ} \mathrm{W}-40^{\circ} \mathrm{E}\right.$ and $\left.20-40^{\circ} \mathrm{N}\right)$ and for $1989-2008$.

tigated in the following. Since the emitted mass associated with cyclones is relatively small south of $20^{\circ} \mathrm{N}$ in general (Sect. 3.6.1), only the northern sub-domain is taken into account. Here, dust emission is analysed in four quadrants, the positions of which follow their geographical orientation depicted in Fig. 14.

Figure 14 shows the annual cycle of the fraction of dust emission per quadrant of the cyclones north of $20^{\circ} \mathrm{N}$ spatially averaged. The results highlight that most dust is emitted in the northern quadrants with typical mean values of 30-55\% between November and March. In April, dust emission prevails in the northeast and southeast with about $30 \%$ contribution each. Dust emission associated with cyclones in May is roughly equally distributed across the quadrants. June to September have clear maxima of dust emission in the southwest with 60-80\%. The total mass emitted between June and September, however, is smaller than at the beginning of the year. Cyclones in October have most dust emission in the southeast, but the integrated mass of dust emission is smallest during autumn (Fig. 11d).

These results can be linked with the position of the highest wind speeds. In the case of a well-defined extratropical cyclone, the cold front typically lies to the west of the cyclone centre initially and moves towards the south and east thereafter. Peak winds, and therefore dust emission, are most likely at and behind the cool front as well as close to the cyclone centre due to the increased horizontal gradient of the geopotential height in these areas. Dust emission would primarily occur in the southwest initially, followed by prevailing emission in the southeast. At a later life stage, an extratropical cyclone typically forms an occlusion causing peak winds near the cyclone core. Dust emission may then form in all 
quadrants similarly. Integrated over the entire life time, most dust emission may be expected in southern quadrants if the cyclone has an extratropical character. While this is not found for the spatial average, examination of the spatial distribution of dust emission per quadrant (not shown) reveals that areas south of the Atlas Mountains show indeed more than $50 \%$ of the dust emission in the southwest or southeast quadrants between February and May. This distribution complies with the expectation for extratropical cyclones. However, the lack of a southern maximum in the spatial mean in winter and spring suggests that cyclones do not show typical characteristics of extratropical cyclones everywhere. Evaluating the spatial distribution of the dust emission per quadrant shows that dust emission in northern quadrants primarily occur in the central Sahara during spring. Here, the heat low lies typically to the south and relatively higher pressure northwards. This implies that instead of a classical frontal structure, a large horizontal gradient in the geopotential height occurs at the northern side of a large fraction of cyclones.

Summertime dust emission is mainly situated in the southwest of the cyclone centre in the spatial mean. Over West Africa, even larger emission fractions of up to $90 \%$ occur in the southwest (not shown). The majority of cyclones during this season live particularly long and migrate westwards (Fig. 6a,c) pointing to surface signatures of AEWs. The dominant quadrant during this time of year is well in agreement with the position of emission ahead of AEWs where NLLJs are expected (Knippertz and Todd, 2010). The automated detection algorithm of Fiedler et al. (2013) is used for estimating the mean fraction of dust emission within the cyclone-affected area that coincide with the occurrence of NLLJs. The result suggests peak contributions from NLLJs to the dust emission associated with cyclones of 10-30\% over parts in West Africa (not shown). Another important driver for dust emission in association with AEWs are haboobs typically developing to the east of an AEW (Knippertz and Todd, 2010). Their missing physical parameterization may cause an underestimation of the dust emission to the east of AEWs. The diurnal cycle of dust emission indicates driving mechanisms on a sub-daily scale that is analysed next.

\subsubsection{Diurnal cycle}

Figure 15b shows the annual cycle of the total dust emission for different times of the day within the cyclone-affected area north of $20^{\circ} \mathrm{N}$. Cyclones are associated with the largest amount of mineral dust in late winter and spring. Maxima are $90-110 \mathrm{~g} \mathrm{~m}^{-2}$ in March, and $70-90 \mathrm{~g} \mathrm{~m}^{-2}$ in May in contrast to values below $20 \mathrm{~g} \mathrm{~m}^{-2}$ between June and January (Fig. 15b). The dust emission during the influence of cyclones has a diurnal cycle with a distinct maximum during the daytime. Emission at night has typical values around $10 \mathrm{~g} \mathrm{~m}^{-2}$ and never exceeds $30 \mathrm{~g} \mathrm{~m}^{-2}$ during spring (Fig. 15b). At 09:00 UTC dust emission is often twice as

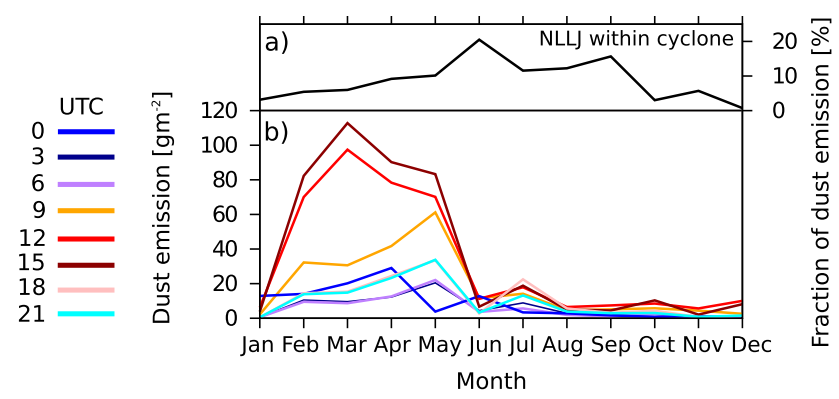

Figure 15. Total dust emission amount associated with long-lived and migrating cyclones. Annual cycle of (a) the fraction of dust emission associated with cyclones and NLLJs and (b) the total dust emission associated with cyclones at different times of the day (colours). Values are spatially integrated over the northern subdomain $\left(15^{\circ} \mathrm{W}-40^{\circ} \mathrm{E}\right.$ and $\left.20-40^{\circ} \mathrm{N}\right)$ and monthly averaged over 1989-2008. NLLJ events are identified as in Fiedler et al. (2013).

large with maximum values of $60 \mathrm{~g} \mathrm{~m}^{-2}$ in May. Emissions at 12:00 and 15:00 UTC are even larger by a factor of two to four.

These diurnal differences for late winter and spring in the north can be explained by the development of the boundary layer in the context of the synoptic-scale conditions. Dust emission occurs when the momentum transport to the surface is sufficiently large to exceed the threshold for emission onset. Reduced stability during the day enables downward turbulent momentum transport, which increases the nearsurface wind speed. This effect is expected to be largest when the daytime boundary layer is sufficiently deep to reach layers of high wind speed in the free troposphere. Strong winds prevail relatively close to the surface during cyclone passage in winter and spring. These cyclones form in a baroclinic zone between the warm (deep) North African air mass compared to the cold (shallow) air polewards. The contrast between the air masses causes a particularly strong thermal wind, i.e. an increase of the geostrophic wind with height in the lower troposphere. Along with typically deep daytime boundary layers over North Africa, momentum from the free troposphere is efficiently transported towards the surface. In the Sahara, the boundary layer reaches a sufficiently large depth at or closely after midday (Culf, 1992), which coincides well with the midday peak of dust emission found here. The time of maximum dust emission is in agreement with the observation of suspended dust in cyclones shown in Fig. 1.

The emission flux at 09:00 UTC in May, however, is almost as large as the midday values, pointing to embedded NLLJs as a driving mechanism. Figure 15a shows the fraction of dust emission within the cyclone-affected area that is associated with NLLJs. The latter are defined and automatically identified as in Fiedler et al. (2013). Based on these results, dust-emitting NLLJs are not frequently embedded in the cyclone-affected area with less than $10 \%$ in winter and spring. This finding is in agreement with the generally small 


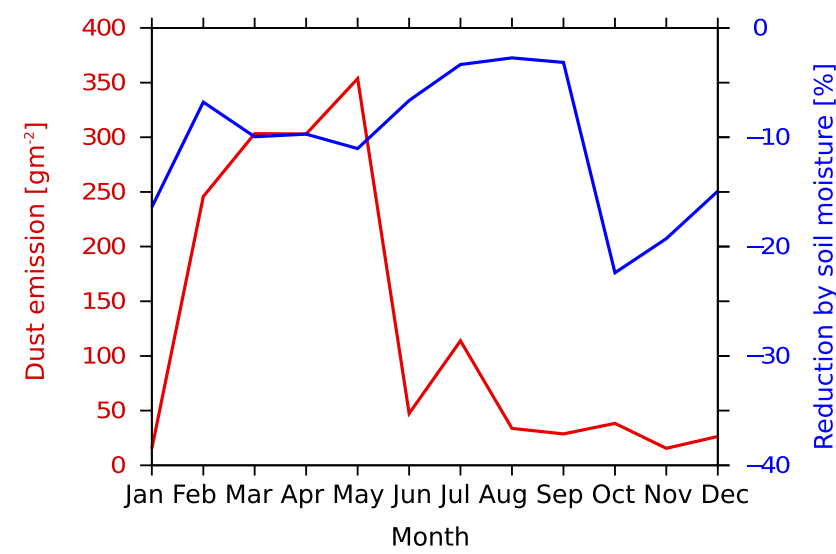

Figure 16. Dust emission amount associated with long-lived and migrating cyclones but weakened by soil moisture. Annual cycle of the total dust emission (red) and the fraction of dust emission suppressed by soil moisture in the cyclone-affected area (blue). Values are spatially integrated over the northern sub-domain $\left(15^{\circ} \mathrm{W}-40^{\circ} \mathrm{E}\right.$ and $20-40^{\circ} \mathrm{N}$ ) and monthly averaged over 1989-2008.

dust emission amount associated with NLLJs during winter and spring in the north (Fiedler et al., 2013). The larger dust emission flux from cyclones at 09:00 UTC in May is, therefore, not predominantly linked to NLLJs. It seems most plausible that the momentum from the free troposphere is more efficiently mixed downwards in May than earlier in spring and winter. This is likely caused by a larger solar irradiation and longer days in late spring, aiding the development of the daytime boundary layer. NLLJs that can be embedded in AEWs are linked to $20 \%$ of the dust emission in the cyclone-affected area in June and around $10 \%$ in July and August.

\subsubsection{Impact of soil moisture}

While arid conditions prevail in North Africa, cyclones can produce rainfall that feeds soil moisture. The presence of soil moisture may weaken or suppress dust emission. The magnitude of this effect is studied with two dust emission calculations with and without accounting for soil moisture, respectively (Sect. 2.2). Figure 16 shows the annual cycle of the fraction of dust emission suppressed by the presence of soil moisture along with the total dust emission when moisture is taken into account as a benchmark. During late winter and spring, the time when dust emission associated with cyclones shows a clear maximum of $250-380 \mathrm{~g} \mathrm{~m}^{-2}$, soil moisture suppresses roughly $10 \%$ of the dust emission spatially averaged across the north. Other months show values ranging from 5 to $20 \%$, but the total dust emission is smaller than $100 \mathrm{~g} \mathrm{~m}^{-2}$ in July and smaller than $80 \mathrm{~g} \mathrm{~m}^{-2}$ during the rest of the year. It is interesting that the value for the emission reduction by soil moisture during cyclone passage for the 20-year period is of the same order of magnitude as the soil moisture effect for haboobs in a 40-day convection-permitting regional simulation for August 2006 (Heinold et al., 2013) despite the underestimation of precipitation and soil moisture over West Africa in August 2006 by the ECMWF model (Agusti-Panareda et al., 2010, and references therein).

\subsection{Emission intensity}

\subsubsection{Anomaly factor}

Despite a small total dust emission amount associated with cyclones, intense emission fluxes are regularly associated with mobile cyclones in spring (Fig. 13b). This aspect of emission intensity is analysed further by defining a dust emission anomaly as the quotient of the dust emission associated with cyclones and the 20-year mean of the dust emission flux in the same month. Figure 17 shows this anomaly factor for both depressions and cyclones along with the dust emission flux spatially averaged across dust-emitting grid boxes. The largest dust emission fluxes occur between February and May with values larger than $1.5 \times 10^{-6} \mathrm{~g} \mathrm{~m}^{-2} \mathrm{~s}^{-1}$. During this time of year the largest total dust emission occurs over the north (Fiedler et al., 2013). The anomaly factor of cyclones during these months has values between four and eight, i.e. the dust emission associated with springtime cyclones is four to eight times larger than the long-term mean of the dust emission flux.

From March to May, the anomaly factor of cyclones even exceeds the values for depressions pointing to mobile cyclones as an important source for intense emission in spring. The dust emission is generally smaller during summer with fluxes of $0.7-1.3 \times 10^{-6} \mathrm{~g} \mathrm{~m}^{-2} \mathrm{~s}^{-1}$ while the anomaly factors of cyclones increases to values of five to nine. During July the anomaly factor of cyclones is, herein, larger than the one of depressions. Even larger anomaly factors of cyclones exceeding the values for depressions are found between September and November with up to 20, but both the dust emission flux and the number of cyclones is then smallest. These results underline that even though the total emission associated with migrating cyclones is rather small compared to the absolute emission in the north, the emission events during cyclone passage are intense.

\subsubsection{Temporal development}

Monitoring dust emission associated with cyclones during different stages of their life (not shown) reveals that dust emission does not occur during the entire time and does not show the same development in each case. The different behaviour is not surprising given (1) the influence of the meteorological development of cyclones that affect the strength of near-surface winds, (2) the various manifestations of North African cyclones that can deviate from a classical frontal structure of an extratropical cyclone (Sect. 3.6.2) and (3) the surface properties that limit dust emission (Sect. 3.6.4). 


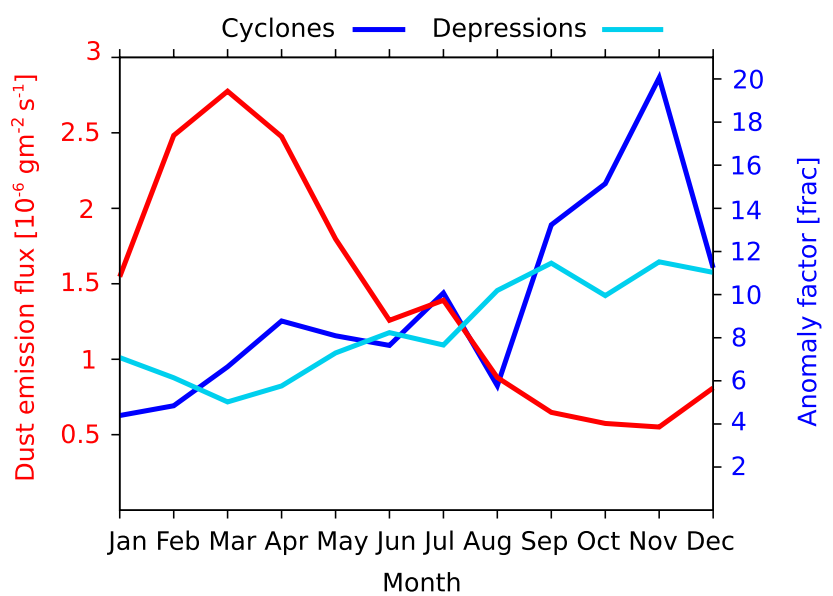

Figure 17. Intensity of dust emission fluxes associated with longlived, migrating cyclones and atmospheric depressions. Annual cycle of the dust emission flux associated with cyclones (red) and the anomaly factor of cyclones (blue) and depressions (cyan) averaged over dust-emitting grid boxes for 1989-2008. The anomaly factor is a measure of emission intensity and defined as the quotient of the dust emission flux associated with the cyclone/depression and the 20-year mean of the dust emission flux of the same month.

These differences do not allow general conclusions on the temporal development of the emission intensity associated with the identified cyclones. The largest dust emission fluxes, however, occur when the system is mature enough to generate strong near-surface winds over dust sources. Emissions at midday are, herein, likely larger than nocturnal values indicated by the total emission associated with cyclones (Fig. 15). Irregular emission intensities are also expected for depressions. Emission intensities within the depressionaffected area varies on sub-daily timescales since NLLJs are embedded (Sect. 3.5). Intense emission fluxes associated with NLLJs are primarily expected during the mid-morning while nocturnal emission is small due to a weaker vertical momentum transport compared to daytime (e.g. Fiedler et al., 2013; Schepanski et al., 2009).

\section{Conclusions}

The present work provides the first climatological estimate of the amount of dust emission associated with atmospheric depressions and mobile, long-lived cyclones over North Africa for 1989-2008. Atmospheric depressions are tracked following the method of Schepanski and Knippertz (2011). While these depressions may be stationary or mobile with varying life times, a sub-class called cyclones is defined which has to fulfil a set of filter criteria, namely a horizontal displacement larger $5^{\circ}$ per day, a lifetime longer than $48 \mathrm{~h}$ and a decreasing core pressure during the first day. The key findings from the depression and cyclone climatologies are:
1. depressions are abundant over North Africa due to the frequent formation of lee troughs in spring and heat lows in summer with a maximum occurrence frequency of $40 \%$, while the occurrence frequency of cyclones is smaller by at least a factor of ten. This suggests that only few depressions become migrating and long-lived cyclones.

2. The cyclone climatology highlights that $37 \%$ of cyclones affecting North Africa occur in spring. Their centres most frequently lie north of $20^{\circ} \mathrm{N}$ with a clear cyclone track stretching from south of the Atlas Mountains towards the eastern Mediterranean in agreement with previous studies (Alpert et al., 1990; Hannachi et al., 2011; Thorncroft and Hodges, 2000; Trigo et al., 1999; Maheras et al., 2001). Springtime cyclones predominantly migrate eastwards, and live for three to seven days. Their year-to-year variability is largest during this season.

Dust emission is simulated with the model by Tegen et al. (2002) driven by ERA-Interim forecasts which show large values north of $20^{\circ} \mathrm{N}$ for December to May (Fiedler et al., 2013). The comparison of the modelled DSAF against the satellite product from Schepanski et al. (2012) shows good agreement in the Bodélé Depression as a key region for dust emission, but differences in the north and west of North Africa. These may be partly due to missed dust detection in the satellite product due to the presence of clouds and atmospheric moisture (Schepanski et al., 2009; Brindley et al., 2012), or limitations of the representation of dust emission and winds in the model setup used.

Dust emission amounts are associated with depressions and cyclones when they occur within a radius of 10 degrees from the centres. The highlights of the results are:

1. depressions coincide with $55 \%$ of the dust emission annually and spatially averaged over North African dust sources. Regionally and seasonally up to $90 \%$ of the dust emission amount is associated with them. Embedded mechanisms such as the NLLJ, defined as in Fiedler et al. (2013), coincide with $12 \%$ of the dust emission associated with depressions annually and spatially averaged. This result is in agreement with Fiedler et al. (2013) who show that NLLJs form frequently along the margins of the Saharan heat low.

2. In contrast to depressions, migrating and long-lived cyclones are rarer and associated with only $4 \%$ of the dust emission annually and spatially averaged. The largest emission coinciding with cyclones is found during spring over wide areas in Libya and small areas south of the Atlas mountains with $15-25 \%$.

3. In summer, AEWs are associated with $5-15 \%$ of the dust emission amount in parts of West Africa. Here, 
AEWs amplify sufficiently to form a signature close to the surface (Thorncroft and Hodges, 2000). The majority of the emissions within the cyclone-affected area are found in the southwestern quadrant of the AEW signature, i.e. the sector with northerly winds and potential NLLJ formation (Knippertz and Todd, 2010). NLLJs coincide with 10-20\% of the monthly emissions associated with cyclones during summer while less than $10 \%$ coincide with NLLJs and cyclones during the rest of the year. Larger dust emissions at the eastern side of AEWs would be expected if haboobs were represented more realistically. Their missing parameterization and an underestimated strength of AEWs (Agusti-Panareda et al., 2010) probably implies an underestimation of associated winds and dust emission.

4. Despite the small total emission amount associated with cyclones, their emission flux magnitude is particularly intense. The dust emission flux during cyclone passage is larger than the climatological mean by a factor of four to eight and is often larger than for depressions.

5. The dust emission associated with springtime cyclones is substantially larger during midday than at night by a factor of three to five. This result suggests that the growth of the boundary layer into the baroclinic zone of the cyclone is important for generating near-surface winds that are strong enough to mobilize mineral dust.

6. The reduction of dust emission through soil moisture is rather small with values of the order of $10 \%$.

In conclusion, the influence of depressions is important for dust emission in North Africa throughout the year although their influence on dust emission may be partly indirect through processes acting on smaller scales. Cyclones are comparably rare and are not associated with a substantial dust emission amount in most regions. However, cyclones generate intense dust emission fluxes exceeding the intensity associated with depressions in most months. Large parts of the climatological dust emission maximum between November and May north of $20^{\circ} \mathrm{N}$ shown in Fiedler et al. (2013) are not associated with depressions and cyclones investigated here. Harmattan surges developing in consequence of post cold frontal ridging are proposed as another mechanism capable of emitting large amounts of dust aerosol. This dust storm type will be the subject of future work.

Acknowledgements. This work is funded by the European Research Council project "Desert Storms" under grant number 257543. We acknowledge support by Deutsche Forschungsgemeinschaft and Open Access Publishing Fund of Karlsruhe Institute of Technology. We would like to thank the European Centre for Medium-Range Weather Forecasts and the UK Met Office for providing and granting access to ERA-Interim data, respectively. We thank EUMETSAT for providing MSG SEVIRI images for North Africa and H. Wernli, ETH Zürich, for the use of the tracking algorithm. We also thank the anonymous reviewers and the journal editor $\mathrm{H}$. Wernli for their comments that helped to improve the manuscript.

Edited by: H. Wernli

\section{References}

Agusti-Panareda, A., Beljaars, A., Cardinali, C., Genkova, I., and Thorncroft, C.: Impacts of Assimilating AMMA Soundings on ECMWF Analyses and Forecasts, Weather Forecast., 25, 11421160, doi:10.1175/2010WAF2222370.1, 2010.

Alpert, P. and Ziv, B.: The Sharav cyclone: observations and some theoretical considerations, J. Geophys. Res., 94, 18495-18514, 1989.

Alpert, P., Neeman, B. U., and Shayel, Y.: Climatological analysis of Mediterranean cyclones using ECMWF data, Tellus A, 42, 6577, doi:10.1034/j.1600-0870.1990.00007.x, 1990.

Ashpole, I. and Washington, R. : A new high-resolution central and western Saharan summertime dust source map from automated satellite dust plume tracking, J. Geophys. Res.-Atmos., 118, 6981-6995, doi:10.1002/jgrd.50554, 2013.

Bou Karam, D., Flamant, C., Tulet, P., Todd, M.C., Pelon, J., and Williams, E.: Dry cyclogenesis and dust mobilization in the intertropical discontinuity of the West African Monsoon: A case study, J. Geophys. Res.-Atmos., 114, D05115, doi:10.1029/2008JD010952, 2009.

Bou Karam, D., Flamant, C., Cuesta, J., Pelon, J., and Williams, E.: Dust emission and transport associated with a Saharan depression: February 2007 case, J. Geophys. Res.-Atmos., 115, D00H27, doi:10.1029/2009JD012390, 2010.

Brindley, H., Knippertz, P., Ryder, C., and Ashpole, I.: A critical evaluation of the ability of the Spinning Enhanced Visible and Infrared Imager (SEVIRI) thermal infrared red-green-blue rendering to identify dust events: Theoretical analysis, J. Geophys. Res.-Atmos., 117, D07201, doi:10.1029/2011JD017326, 2012.

Burpee, R. W.: The origin and structure of Easterly Waves in the lower troposphere of North Africa, J. Atmos. Sci., 29, 77-90, 1972.

Carslaw, K. S., Boucher, O., Spracklen, D. V., Mann, G. W., Rae, J. G. L., Woodward, S., and Kulmala, M.: A review of natural aerosol interactions and feedbacks within the Earth system, Atmos. Chem. Phys., 10, 1701-1737, doi:10.5194/acp-10-17012010, 2010.

Cornelis, W. M. and Gabriels, D.: The effect of surface moisture on the entrainment of dune sand by wind: an evaluation of selected models., Sedimentology, 50, 771-790, doi:10.1046/j.1365-3091.2003.00577.x, 2003.

Culf, A. D.: An application of simple models to Sahelian convective boundary-layer growth, Bound.-Lay. Meteorol., 58, 1-18, doi:10.1007/BF00120748, 1992.

Decker, M., Brunke, M. A., Wang, Z., Sakaguchi, K., Zeng, X., and Bosilovich, M. G.: Evaluation of the Reanalysis Products from GFSC, NCEP and ECMWF Using Flux Tower Observations, J. Climate, 25, 1916-1944, 2012.

Dee, D. P., Uppala, S. M., Simmons, A. J., Berrisford, P., Poli, P., Kobayashi, S., Andrae, U., Balmaseda, M. A., Balsamo, G., Bauer, P., Bechtold, P., Beljaars, A. C. M., van de Berg, L., Bidlot, J., Bormann, N., Delsol, C., Dragani, R., Fuentes, M., Geer, 
A. J., Haimberger, L., Healy, S. B., Hersbach, H., Hólm, E. V., Isaksen, L., Kållberg, P., Köhler, M., Matricardi, M., McNally, A. P., Monge-Sanz, B. M., Morcrette, J.-J., Park, B.-K., Peubey, C., de Rosnay, P., Tavolato, C., Thépaut, J.-N., and Vitart, F.: The ERA-Interim reanalysis: configuration and performance of the data assimilation system, Q. J. Roy. Meteor. Soc., 137, 553-597, doi:10.1002/qj.828, 2011.

Fécan, F., Marticorena, B., and Bergametti, G.: Parametrization of the increase of the aeolian erosion threshold wind friction velocity due to soil moisture for arid and semi-arid areas, Ann. Geophys., 17, 149-157, doi:10.1007/s00585-999-0149-7, 1999.

Fiedler, S., Schepanski, K., Heinold, B., Knippertz, P., and Tegen, I.: Climatology of nocturnal low-level jets over North Africa and implications for modeling mineral dust emission, J. Geophys. Res.-Atmos., 118, 6100-6121, doi:10.1002/jgrd.50394, 2013.

Hannachi, A., Awad, A., and Ammar, K.: Climatology and classification of Spring Saharan cyclone tracks, Clim. Dynam., 37, 473-491, doi:10.1007/s00382-010-0941-9, 2011.

Heinold, B., Tegen, I., Schepanski, K., Tesche, M., Esselborn, M., Freudenthaler, V., Gross, S., Kandler, K., Knippertz, P., Müller, D., Schladitz, A., Toledano, C., Weinzierl, B., Ansmann, A., Althausen, D., Müller, T., Petzold, A., and Wiedensohler, A.: Regional modelling of Saharan dust and biomass-burning smoke Part I: Model description and evaluation, Tellus B, 63, 781-799, doi:10.1111/j.1600-0889.2011.00570.x, 2011.

Heinold, B., Knippertz, P., Marsham, J. H., Fiedler, S., Dixon, N. S., Schepanski, K., Laurent, B., and Tegen, I.: The role of deep convection and nocturnal low-level jets for dust emission in summertimeWest Africa: Estimates from convectionpermitting simulations, J. Geophys. Res.-Atmos., 118, 43854400, doi:10.1002/jgrd.50402, 2013.

Hodges, K. I., Lee, R. W., and Bengtsson, L.: A comparison of extratropical cyclones in recent reanalysis ERA-Interim, NASA MERRA, NCEP CFSR, and JRA-25, J. Climate, 24, 4888-4906, doi:10.1175/2011JCLI4097.1, 2011.

Homar, V. and Stensrud, D. J.: Sensitivities of an intense Mediterranean cyclone: Analysis and validation, Q. J. Roy. Meteor. Soc., 130, 2519-2540, doi:10.1256/qj.03.85, 2004.

Homar, V., Ramis, C., and Alonso, S.: A deep cyclone of African origin over the Western Mediterranean: diagnosis and numerical simulation, Ann. Geophys., 20, 93-106, doi:10.5194/angeo-2093-2002, 2002.

Homar, V., Jansà, A., Campins, J., Genovés, A., and Ramis, C.: Towards a systematic climatology of sensitivities of Mediterranean high impact weather: a contribution based on intense cyclones, Nat. Hazards Earth Syst. Sci., 7, 445-454, doi:10.5194/nhess-7445-2007, 2007.

Hopsch, S. B., Thorncroft, C. D., Hodges, K., and Aiyyer, A.: West African storm tracks and their relationship to Atlantic tropical cyclones, J. Climate, 20, 2468-2483, doi:10.1175/JCLI4139.1, 2007.

Huneeus, N., Schulz, M., Balkanski, Y., Griesfeller, J., Prospero, J., Kinne, S., Bauer, S., Boucher, O., Chin, M., Dentener, F., Diehl, T., Easter, R., Fillmore, D., Ghan, S., Ginoux, P., Grini, A., Horowitz, L., Koch, D., Krol, M. C., Landing, W., Liu, X., Mahowald, N., Miller, R., Morcrette, J.-J., Myhre, G., Penner, J., Perlwitz, J., Stier, P., Takemura, T., and Zender, C. S.: Global dust model intercomparison in AeroCom phase I, Atmos. Chem. Phys., 11, 7781-7816, doi:10.5194/acp-11-7781-2011, 2011.
Jones, C., Mahowald, N., and Luo, C.: The role of easterly waves on African desert dust transport, J. Climate, 16, 3617-3628, 2003.

Kahana, R., Ziv, B., Enzel, Y., and Dayan, U.: Synoptic climatology of major floods in the Negev Desert, Israel, Int. J. Climatol., 22, 867-882, doi:10.1002/joc.766, 2002.

Klose, M., Shao, Y., Karremann, M. K., and Fink, A.: Sahel dust zone and synoptic background, Geophys. Res. Lett., 37, L09802, doi:10.1029/2010GL042816, 2010.

Knippertz, P. and Fink, A. H.: Synoptic and dynamic aspects of an extreme springtime Saharan dust outbreak., Q. J. Roy. Meteor. Soc., 132, 1153-1177, 2006.

Knippertz, P. and Todd, M.: The central west Saharan dust hot spot and its relation to African easterly waves and extratropical disturbances, J. Geophys. Res.-Atmos., 115, D12117, doi:10.1029/2009JD012819, 2010.

Knippertz, P. and Todd, M. C.: Mineral dust aerosol over the Sahara: Processes of Emission and Transport, and Implifications for modeling., Rev. Geophys., RG1007, doi:10.1029/2011RG000362, 2012.

Kok, J. F., Parteli, E. J., Michaels, T. I., and Karam, D. B.: The physics of wind-blown sand and dust, Rep. Prog. Phys., 75, 106901, doi:doi:10.1088/0034-4885/75/10/106901, 2012.

Laurent, B., Tegen, I., Heinold, B., Schepanski, K., Weinzierl, B., and Esselborn, M.: A model study of Saharan dust emission and distributions during the SAMUM-1 campaign, J. Geophys. Res., 115, D21210, doi:10.1029/2009JD012995, 2010.

Lavaysse, C., Flamant, C., Janicot, S., Parker, D. J., Lafore, J.-P., Sultan, B., and Pelon, J.: Seasonal evolution of the West African heat low: a climatological perspective, Clim. Dynam., 33, 313330, 2009.

Leroux, S., Hall, N. M. J., and Kiladis, G. N.: Intermittent African Easterly Wave Activity in a Dry Atmospheric Model: Influence of the Extratropics., J. Climate, 24, 5378-5396, doi:10.1175/JCLI-D-11-00049.1, 2011.

Luo, C., Mahowald, N., and Jones, C.: Temporal variability of dust mobilization and concentration in source regions, J. Geophys. Res., 109, D20202, doi:10.1029/2004JD004861, 2004.

Maheras, P., Flocas, H., Patrikas, I., and Anagnostopoulou, C.: A 40 year objective climatology of surface cyclones in the Mediterranean region: Spatial and temporal distribution, Int. J. Climatol., 21, 109-130, doi:10.1002/joc.599, 2001.

Marsham, J. H., Knippertz, P., Dickson, N., Parker, D. J., and Lister, G.: The importance of the representation of deep convection for modeled dust-generating winds over West Africa during summer, Geophys. Res. Lett., 38, L16803, doi:10.1029/2011GL048368, 2011.

Marsham, J. H., Dixon, N. S., Garcia-Carreras, L., Lister, G. M. S., Parker, D. J., Knippertz, P., and Birch, C. E: The role of moist convection in the West African monsoon system: Insights from continental-scale convection-permitting simulations, Geophys. Res. Lett., 40, 1843-1849, doi:10.1002/grl.50347, 2013.

Marticorena, B. and Bergametti, G.: Modelling the atmospheric dust cycle. 1: Design of a soilderived dust emission scheme, J. Geophys. Res., 100, 16415-16430, 1995.

Mekonnen, A., Thorncroft, C. D., and Aiyyer, A. R.: Analysis of Convection and its Association with African Easterly Waves, J. Climate, 19, 5404-5421, 2006.

Moulin, C., Lambert, C. . E., Dayan, U. ., Masson, V. ., Ramonet, M. ., Bousquet, P. ., Legrand, M., Balkanski, Y. J., Guelle, W., 
Marticorena, B., Bergametti, G., and Dulac, F.: Satellite climatology of African dust transport in the Mediterranean atmosphere, J. Geophys. Res, 103, 13137-13144, 1998.

Pedgley, D.: Desert depression over northeast Africa, Meteorol. Mag., 101, 228-244, 1972.

Schepanski, K., Tegen, I., Laurent, B., Heinold, B., and Macke, A.: A new Saharan dust source activation frequency map derived from MSG-SEVIRI IR-channels, Geophys. Res. Lett., 34, L18803, doi:10.1029/2007GL030168, 2007.

Schepanski, K., Tegen, I., Todd, M., Heinold, B., Bönisch, G., Laurent, B., and Macke, A.: Meteorological processes forcing Saharan dust emission inferred from MSG-SEVERI observations of subdaily dust source activation and numerical models, J. Geophys. Res., 114, D10201, doi:10.1029/2008JD010325, 2009.

Schepanski, K. and Knippertz, P.: Soudano-Saharan depressions and their importance for precipitation and dust: a new perspective on a classical synoptic concept, Q. J. Roy. Meteor. Soc., 137, 1431-1445, doi:10.1002/qj.850, 2011.

Schepanski, K., Tegen, I., and Macke, A. Comparison of satellite based observations of Saharan dust source areas, Remote Sens. Environ., 123, 90-97, doi:10.1016/j.rse.2012.03.019, 2012.

Shao, Y., Wyrwoll, K.-H., Chappell, A., Huang, J., Lin, Z., McTrainsh, G. H., Mikami, M., Tanaka, T. Y., Wang, X., and Yoon, S.: Dust cycle: A emerging core theme in Eaerth system science, Aerolian Res., 2, 181-204, 2011.

Tegen, I., Harrison, S., Kohfeld, K., Prentice, I., Coe, M., and Heimann, M.: Impact of vegetation and preferential source areas on global dust aerosols: Results from a model study, J. Geophys. Res., 107, 4576, doi:10.1029/2001JD000963, 2002.

Tegen, I., Schepanski, K., and Heinold, B.: Comparing two years of Saharan dust source activation obtained by regional modelling and satellite observations, Atmos. Chem. Phys., 13, 2381-2390, doi:10.5194/acp-13-2381-2013, 2013.
Thorncroft, C. D. and Hodges, K.: African Easterly Wave Variability and Its Relationship to Atlantic Tropical Cyclone Activity, J. Climate, 14, 1166-1179, 2000.

Thorncroft, C. D., Hall, N. M. J., and Kiladis, G. N.: Threedimensional structure and dynamics of African Easterly Waves. Part III: Genesis, J. Atmos. Sci., 65, 3596-3607, doi:10.1175/2008JAS2575.1, 2008.

Todd, M., Allen, C., Bart, M., Bechir, M., Bentefouet, J., Brooks, B., Cavazos-Guerra, C., Clovis, T., Deyane, S., Dieh, M., Engelstaedter, S., Flamant, C., Garcia-Carreras, L., Gandega, A., Gascoyne, M., Hobby, M., Kocha, C., Lavaysse, C., Marsham, J., Martins, J., McQuaid, J., Ngamini, J. B., Parker, D., Podvin, T., Rocha-Lima, A., Traore, S., Wang, Y., and Washington, R.: Meteorological and dust aerosol conditions over the Western Saharan region observed at Fennec supersite-2 during the Intensive Observation Period in June 2011, J. Geophys. Res.-Atmos., 118, 8426-8447, doi:10.1002/jgrd.50470, 2013.

Trigo, I. F., Davies, T. D., and Bigg, G. R.: Objective Climatology of Cyclones in the Mediterranean Region, J. Climate, 12, 16851696, 1999.

Trigo, I. F., Bigg, G. R., and Davies, T. D.: Climatology of Cyclogenesis Mechanisms in the Mediterranean, Mon. Weather Rev. 130, 549-569, 2002.

Wernli, H. and Schwierz, C.: Surface Cyclones in the ERA40 Dataset (1958-2001). Part I: Novel Identification Method and Global Climatology, J. Atmos. Sci., 63, 2486-2507, doi:10.1175/JAS3766.1, 2006.

Winstanley, D.: Sharav, Weather, 27, 146-160, doi:10.1002/j.14778696.1972.tb04279.x, 1972.

Zhang, K., O’Donnell, D., Kazil, J., Stier, P., Kinne, S., Lohmann, U., Ferrachat, S., Croft, B., Quaas, J., Wan, H., Rast, S., and Feichter, J.: The global aerosol-climate model ECHAM-HAM, version 2: sensitivity to improvements in process representations, Atmos. Chem. Phys., 12, 8911-8949, doi:10.5194/acp-12-89112012, 2012. 